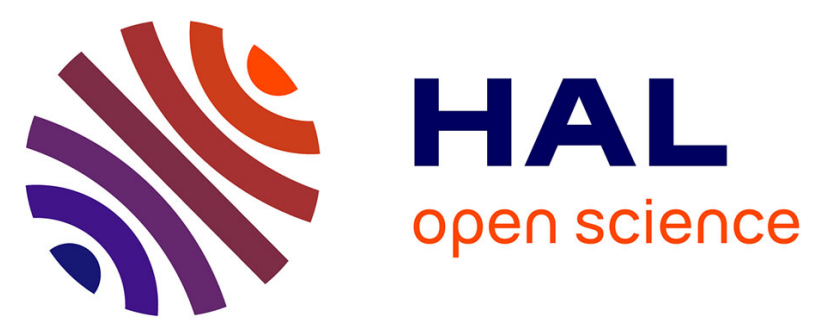

\title{
Genetic structure of European flounder Platichthys flesus: effects of both the southern limit of the species' range and chemical stress
}

Isabelle Calves, Edouard Lavergne, Anne-Leila Meistertzheim, Grégory

Charrier, Henrique Cabral, Bruno Guinand, Louis Quiniou, Jean Laroche

\section{To cite this version:}

Isabelle Calves, Edouard Lavergne, Anne-Leila Meistertzheim, Grégory Charrier, Henrique Cabral, et al.. Genetic structure of European flounder Platichthys flesus: effects of both the southern limit of the species' range and chemical stress. Marine Ecology Progress Series, 2013, 472, pp.257-273. 10.3354/meps09797 . hal-00778167

\section{HAL Id: hal-00778167 \\ https://hal.univ-brest.fr/hal-00778167}

Submitted on 18 Jan 2013

HAL is a multi-disciplinary open access archive for the deposit and dissemination of scientific research documents, whether they are published or not. The documents may come from teaching and research institutions in France or abroad, or from public or private research centers.
L'archive ouverte pluridisciplinaire HAL, est destinée au dépôt et à la diffusion de documents scientifiques de niveau recherche, publiés ou non, émanant des établissements d'enseignement et de recherche français ou étrangers, des laboratoires publics ou privés. 
Cite as: Calvès, I., Lavergne, E., Meistertzheim, A.L., Charrier, G., Cabral, H., Guinand, B., Quiniou, L. \& Laroche, J. (2013) Genetic structure of European flounder Platichthys flesus: effects of both the southern limit of the species' range and chemical stress. Marine Ecology Progress Series, 472, 257-273.

DOI: $10.3354 /$ meps09797

\title{
Genetic structure of European flounder Platichthys flesus: effects of both the southern limit of the species' range and chemical stress
}

I. Calvès ${ }^{1}$, E. Lavergne ${ }^{1,2}$, A. L. Meistertzheim ${ }^{3}$, G. Charrier ${ }^{4}$, H. Cabral ${ }^{5}$, B. Guinand ${ }^{6}$, L. Quiniou ${ }^{1}$, J. Laroche ${ }^{1}$

1 Université de Bretagne Occidentale, UMR 6539, CNRS/IRD/UBO, Laboratoire des Sciences de l’Environnement Marin LEMAR, Institut Universitaire Européen de la Mer, Plouzané, France

2 Senckenberg Forschungsinstitut und Naturmuseum, Sektion Ichthyologie, Senckenberganlage 25, 60325 Frankfurt am Main, Germany

3 Centre de Formation et de Recherche sur l'Environnement Méditerranéen (CEFREM), UMR 5110 CNRS/UPVD, Université de Perpignan, France

4 University of Gothenburg, Department of Marine Ecology, Tjärnö, 45296 Strömstad, Sweden

5 Centro de Oceanografia, Campo Grande, 1749-016 Lisboa, Portugal

6 Université de Montpellier II, UMR CNRS 5554, Institut des Sciences de l'Evolution de Montpellier (ISE-M), Département de Biologie Intégrative, Place E. Bataillon, 34095 Montpellier Cedex 5, France

Corresponding author: J. Laroche, $\mathrm{Tel}+33298498626$

Email address: jean.laroche@univ-brest.fr

Address: LEMAR, Rue Dumont d'Urville, 29280 Plouzané, France

\begin{abstract}
The genetic structure of European flounder Platichthys flesus populations was analysed in the southern part of the species' distribution area, from England to Portugal; samples were collected in 5 estuaries which were chosen because of their latitudinal cline, the level of contaminants and the possibility of hypoxia: the Tamar in England; the Canche, Seine and Vilaine in France; and the Mondego in Portugal. Analysing the variability of a mitochondrial marker (cytochrome $c$ oxidase subunit 1), we observed (1) a moderately higher nucleotide diversity in the Tamar and Canche, reflecting the probable existence of a major refugium in this sector during the last glacial maximum, and (2) a reduced genetic differentiation over the whole data set. The use of 8 microsatellites underlined the maintenance of genetic diversity in the peripheral population of the Mondego, located near the southern limit of the species' range; furthermore, significant pairwise differentiations of populations including Mondego underlined the particular genetic status of this Portuguese population. The polymorphism of a candidate gene involved in energetic metabolism, AMP-desaminase isoform 1, was investigated focusing on exon 1; we found the highest heterozygosities in the more polluted populations (Seine, Tamar) and marked differentiations compared to the other group of populations (Mondego, Vilaine, Canche). The pattern of variability observed for the AMPdesaminase suggests that in chronically contaminated flounder populations, cocktails of pollutants act as selective agents directly or indirectly on this locus.
\end{abstract}

Keywords: European flounder, Estuaries, Genetics, Peripheral population, Climate change, Pollution 


\section{Introduction}

Biological factors (life history, demography) and environmental factors (oceanic hydrology, environmental stress and fishing) shape the genetic structure of marine fish populations. Recent genetic studies have demonstrated that population subdivision in marine fishes can be observed at limited geographical scales, ranging from tens to a few hundred kilometers (e.g. Nielsen et al. 2004, Olsen et al. 2008), despite the potential for extensive gene flow between populations in marine ecosystems. Furthermore, the adaptive significance of population structure in marine fishes is becoming evident, based on the divergence of phenotypic traits (Hutchings et al. 2007, Larsen et al. 2007). Efforts to manage and conserve coastal fish species are urgently needed because this resource is particularly subject to (1) increasing impacts of global climate change (Harley et al. 2006) and (2) possible anthropogenic stressors at local scales; thus, the scientific community must better understand how some populations can maintain their resilience in the face of environmental degradation (Sgro et al. 2011).

Estuarine fishes displaying a wide geographical distribution and the ability to cope with contrasting environments are excellent candidates to explore evolution in populations particularly subjected to warming, chemical stress and hypoxia. In this study, we explored the genetic structure of a typical catadromous flatfish, the European flounder Platichthys flesus (Linnaeus, 1758), which spawns at sea from January to March in western Europe and has a pelagic larval life of $1 \mathrm{mo}$ and a juvenile life of approximately $2 \mathrm{yr}$ in estuaries. Homing behaviour was detected for the flounder in the Tamar estuary (England), where most adults return to their original estuarine range after spawning (Dando 2011). Finally, the European flounder is closely linked to naturally fragmented estuarine systems, allowing environmental conditions to produce noticeable phenotypic differences and possibly local adaptations. 
The flounder is widely distributed in Europe from Norway to Portugal, where its abundance has decreased since the early 1990s, particularly in the Tejo estuary (Portugal). This rarefaction in Portuguese waters was associated with an increase in water temperature caused by climate change (Cabral et al. 2007), and at the moment, the distribution of Platichthys flesus in Portugal is limited to the north and central coast. In a northern region, the Bay of Biscay, the negative impact of warming on abundance and occurrence of boreal flatfish species was also clearly detected from 1987 to 2006; indeed, the abundance of northern temperate species, like $P$. flesus, decreased in this region and was negatively correlated with temperatures in their year of birth (Hermant et al. 2010).

Several investigations on the genetic structure of the European flounder have been conducted over the western and northern European coasts, from Finland to Portugal. Regarding allozymes, Borsa et al. (1997) observed (1) a significant but reduced geographic differentiation and (2) a weak pattern of isolation by distance, from the south-western Baltic Sea to southern Portugal. On the other hand, no clear indication of mtDNA differentiation was detected in that study. Using microsatellites on an extensive data set of flounder populations (from Finland to the Bay of Biscay, including western and eastern Baltic), Hemmer-Hansen et al. (2007a) detected a reduced allelic diversity in the extreme parts of the distribution area, and a higher genetic structure than Borsa et al. (1997); they identified several barriers restricting gene flow between Trondheim and Lake Pulmanki, and between Trondheim and the North Sea, and several relatively isolated populations (Faroe Islands, eastern Baltic). In the previous study (Hemmer-Hansen et al., 2007a), the geographical distance was significantly associated with genetic divergence among the subset of samples, excluding the more isolated populations; the authors suggested a potential association between latitude and genetic structuring among the populations in the Atlantic, with the temperature gradient along latitudinal clines being the probable cause for generating such genetic structure. 
Other population genetics investigations on the European flounder suggested that selective pressure due to contamination of estuaries could induce adaptive responses of the populations. Hence, Marchand et al. (2003, 2004, 2010) emphasised an increase in the frequency of particular alleles or genotypes displaying a better capacity to cope with chemical stress, but these authors also demonstrated a physiological cost of tolerance to toxicants. In 2 other studies on Platichthys flesus, Hemmer-Hansen et al. (2007b) and Larsen et al. (2007) confirmed the great capacity of this species to adapt to contrasting environments. These last 2 studies highlighted the genetic basis of the adaptation of flounder to the particular environment of the Baltic Sea compared to the North Sea (reduced salinity, more or less chronic hypoxia, highly variable temperature), by analysing the polymorphism of 1 candidate gene $(H s c 70)$ and using microarray analysis.

In the present study, we analysed the genetic structure of Platichthys flesus in environmentally contrasting estuaries located along a latitudinal cline from England to Portugal (i.e. the southern limit of the distribution area of this northern temperate species). Five estuaries were chosen because of the levels of contaminants, the possibility of hypoxia and the latitudinal cline. Our main objective was to explore the genetic structure of European flounder populations faced with climate change and anthropogenic stressors, using 3 kinds of genetic markers:

(1) A mitochondrial marker, cytochrome $c$ oxidase subunit 1 (CO1), considered to be selectively neutral: the relative haplotype frequencies of $\mathrm{CO} 1$ in different populations were used to infer historical relationships between populations; the mtDNA markers have been successfully applied in phylogeographic studies (Avise 1994), although it is evident that selective pressure can act on them (Ballard \& Melvin 2010);

(2) 8 microsatellites, considered to be selectively neutral: these can be useful markers for phylogeographic studies, but their high variability allowed us to explore the recent 
evolutionary history of populations and to look for possible genetic structure considering regional spatial scales;

(3) Finally, we explored the polymorphism of a new candidate gene, the AMP-deaminase isoform 1 (AMPD1: aminohydrolase, adenosine 5'-monophosphate deaminase, isoform 1, EC 3.5.4.6) involved in the energetic metabolism and particularly in the stabilization of the adenylate energy charge (Chapman \& Atkinson 1973, Yoshino \& Muramaki 1981) and in the control of the purine nucleotide cycle (Lowenstein 1972). AMPD1 variability was analysed in the flounder populations; our hypothesis was that possible selective pressure induced by environmental stress could affect this gene.

\section{Materials and methods}

\section{Field collection}

Juvenile Platichthys flesus (average estimated age $=9$ mo, average total length $=10 \mathrm{~cm}$ ) were trawled from September to November 2009 in 5 European estuaries located along a latitudinal cline: the Tamar (England), the Canche, Seine and Vilaine (France) and the Mondego (Portugal; Fig. 1, Table 1). Approximately 50 fish were collected in each estuary (Table 1), and during the dissection in the field, 1 fin fragment was collected from each fish and stored in $95 \%$ ethanol.

All 5 estuaries presented a latitudinal gradient of temperature and different contaminant loads. The Tamar River (basin area $=10,000 \mathrm{~km}^{2}$ ) is impacted by a high metal contamination linked to ancient mining activities (Pulsford et al. 1992). The Canche (basin area $=1,274 \mathrm{~km}^{2}$ ) is a small estuary characterized by little urban development and no industrialization (Amara et al. 2007), so it is considered as a reference site. The Seine estuary (basin area $=78,650 \mathrm{~km}^{2}$ ) is affected by heavy chemical stress linked to high population density, numerous industrial activities and intensive agriculture across the drainage area (Gilliers 2004, Cachot et al. 2006). 
The Vilaine catchment $\left(\right.$ area $=10,500 \mathrm{~km}^{2}$ ) is mainly subjected to impacts from agricultural activities and thus to pesticide contamination (Forget 1998, SAGE Vilaine 1999). Moreover, a dam is located $12 \mathrm{~km}$ upstream from the mouth of the Vilaine estuary which stops the inflow of saline waters into the system; in summer months, this situation can lead to stratification of the water mass in the estuary and eutrophication, and thus to severe hypoxic crisis (Menesguen et al. 2001). The Mondego catchment (area $=6,670 \mathrm{~km}^{2}$ ) shows a generally reduced eutrophication level, and is subject to moderate levels of toxics linked to agriculture, aquaculture and industrial activities (França et al. 2011).

\section{mtDNA CO1 and AMPD1 variability}

Genomic DNA was extracted from fin clips using AcroPrep $^{\text {тм }}$ 96-well filter plates $(1 \mathrm{ml})$ with $1 \mu \mathrm{m}$ glass fibre media (PALL® 5051), following the protocol of Ivanova et al. (2006).

\section{Choice of markers}

A fragment of the mitochondrial CO1 gene was amplified by real time PCR (qPCR) using the primers Fish-F2 and Fish-R2 (Table 2) described by Ward et al. (2005). These primers amplified a $689 \mathrm{bp}$ region of the CO1 gene. At the same time, a qPCR amplification of a 160 bp region of the AMPD gene (accession number in GenBank: AY660016) previously described (Thebault et al. 2010) was performed using Platichthys flesus-specific primers, PfAMPD1_F and PfAMPD1_R, designed by Primer Express software (Table 2). The AMPD gene of $P$. flesus presents $66 \%$ homology with the humanAMPD1 gene. This gene has a size of $6370 \mathrm{bp}$ from the 5 ' untranslated region to the sequence of the polyA. It contains 12 exons separated by 11 introns. We decided to work on exon 1 (160 bp), because it showed a robust polymorphism in previous work on flounder populations, with 4 genotypes identified by 
single-strand conformation polymorphism in the Seine and Vilaine populations (Meistertzheim pers. obs.).

PCR for high-resolution melting (HRM) analysis

Real time PCR reactions were carried out in 96-well plates on a Light Cycler TM 480 Instrument (Roche) with the primers mentioned in the previous section. The reactions were performed in a $15 \mu \mathrm{l}$ volume containing the HRM master mix (Roche) using the Resolight ${ }^{\circledR}$ set of fluorescent dyes, $3.0 \mathrm{mM} \mathrm{MgCl} 2,0.5 \mu \mathrm{M}$ of each primer and $15 \mathrm{ng}$ of DNA. Reaction mixtures were overlaid with mineral oil to prevent evaporative losses ensuring melting profile uniformity. The amplification protocol consisted of a 10 min pre-incubation at $95^{\circ} \mathrm{C}$, followed by 40 cycles using the following conditions: denaturing step at $95^{\circ} \mathrm{C}$ for $15 \mathrm{~s}$ (ramp rate, $4.4^{\circ} \mathrm{C} \mathrm{s}^{-1}$ ), touchdown annealing from 65 to $53^{\circ} \mathrm{C}$ for $15 \mathrm{~s}$ (ramp rate, $2.2^{\circ} \mathrm{C} \mathrm{s}^{-1}$ ) and extension at $72^{\circ} \mathrm{C}$ for $20 \mathrm{~s}$ (ramp rate, $4.4^{\circ} \mathrm{C} \mathrm{s}^{-1}$ ). The $\mathrm{HRM}$ genotyping method included in the LightCycler 480 v. 1.5 .0 software was used to analyse the PCR products based on the melting curves. Prior to obtaining HRM curves, the PCR products were incubated at $95^{\circ} \mathrm{C}$ for $1 \mathrm{~min}$, followed by a hybridization step of $40^{\circ} \mathrm{C}$ for 1 min. Melting curves were then generated by ramping from 65 to $95^{\circ} \mathrm{C}$ at $0.02^{\circ} \mathrm{C} \mathrm{s}^{-1}$, taking 25 acquisitions per each degree centigrade. HRM curves were plotted using the automated grouping option in the LightCycler $480 \mathrm{v}$. 1.5.0 software. This protocol detects $100 \%$ of heterozygous and $75 \%$ of homozygous variants. Homozygous variants were detected a second time at $100 \%$ by adding wild-type reference DNA in the tube as described previously (Meistertzheim et al. 2012).

\section{Identification of variants}

The Gene Scanning module of the LightCycler 480 v. 1.5 .0 software was designed to improve the discrimination ability between variants. For this purpose, melting curve data were manually adjusted and fluorescence-normalized conditions were established (Meistertzheim et 
al. 2012). Clustering obtained by HRM was compared with the PCR fragment sequence. When all variants had been obtained, a sample of every variant was sequenced to verify the sequence associated with each variant. Thus, 21 variants identified for the $\mathrm{CO} 1$ gene as well as 25 variants identified for the AMPD1 gene were sequenced.

\section{DNA sequencing}

DNA fragments amplified by real time PCR were cleaned using a PCR $\mu 96$ Filter Plate (Millipore) according to the manufacturer's protocol, eluted in $20 \mu \mathrm{l}$ of MilliQ water and sequenced. Sequencing reactions were performed on purified PCR products with the use of the sequencing reagent BigDye V3.1 (Applied Biosystems) and the forward primer previously used for the qPCR assay. The initial phase of denaturation $\left(2 \mathrm{~min}\right.$ at $\left.96^{\circ} \mathrm{C}\right)$ was followed by 40 cycles of $96^{\circ} \mathrm{C}$ for $30 \mathrm{~s}, 50^{\circ} \mathrm{C}$ for $30 \mathrm{~s}$ and $60^{\circ} \mathrm{C}$ for $4 \mathrm{~min}$. The sequences were generated on an ABI 3730 automated sequencer (Applied Biosystems).

\section{Microsatellite variability}

First, 30 previously published Platichthys flesus microsatellites were tested (Dixon 2003, Casas et al. 2005, Tysklind et al. 2009). PCRs were conducted on a GeneAmp PCR system 9700 (Applied Biosystems ${ }^{\mathrm{TM}}$ ) and optimized for each locus on 8 randomly selected samples using specific published primers (forward primers were modified with the addition of a universal tail at the 5' end) and fluorescent dye-labelled universal primers (Schuelke 2000, Chang et al. 2004). PCR products were analysed on $1.5 \%$ agarose gels stained with ethidium bromide. Electrophoresis was performed at $130 \mathrm{~V}$ for approximately $30 \mathrm{~min}$ in $0.5 \%$ TrisBorate-EDTA (TBE) buffer and then visualized under UV light. Only loci with clearly defined bands were retained for subsequent steps. For each selected locus, microsatellite alleles were then visualized using an ABI 3130 Genetic Analyzer (Applied Biosystems ${ }^{\mathrm{TM}}$ ) in 
order to estimate the allele size range and detect potential stuttering. Finally, 8 polymorphic loci presenting low stutter bands were retained for this study: PFSCU1, PFSCU3, PFSCU4, PFSCU7, PFSCU8, STPFL001, STPFL004 and STPFL025 (Dixon 2003, Casas et al. 2005; our Table 2).

To proceed with the routine PCRs and fragment analyses, the 8 forward primers were labelled (Table 2). PCR reactions were performed in a total reaction volume of $10 \mu$, using $1 \mu \mathrm{l}$ of $10 \times$ buffer, $0.40 \mu \mathrm{l}$ of $\mathrm{MgCl}_{2}(25 \mathrm{mM}), 0.37 \mu \mathrm{l}$ of a pool of dNTP ( $2 \mathrm{mM}$, Uptima), $0.05 \mu \mathrm{l}$ of labelled forward primer and reverse primer, $0.05 \mu \mathrm{l}$ of $\mathrm{Taq}$ polymerase $(5000 \mathrm{u}$ Uptima), $1 \mu \mathrm{l}$ of template DNA $\left(5 n g \mathrm{l}^{-1}\right)$ and $6.18 \mu \mathrm{l}$ of MilliQ water. Touchdown PCR conditions consisted of an initial denaturing step at $94^{\circ} \mathrm{C}(3 \mathrm{~min})$ followed by 5 cycles at $94^{\circ} \mathrm{C}$ (30 s), 54 to $49^{\circ} \mathrm{C}\left(30 \mathrm{~s} ;-1^{\circ} \mathrm{C}\right.$ cycle $\left.{ }^{-1}\right)$ and $72^{\circ} \mathrm{C}(30 \mathrm{~s})$, followed by 30 cycles at $94^{\circ} \mathrm{C}(30 \mathrm{~s})$, $53^{\circ} \mathrm{C}(30 \mathrm{~s})$ and $72^{\circ} \mathrm{C}(30 \mathrm{~s})$. A final elongation step at $72^{\circ} \mathrm{C}(5 \mathrm{~min})$ ended the PCR. PCRs were performed as simplex, and PCR products were diluted at $1 / 200$. Three multiplex fragment analyses were performed using $1 \mu \mathrm{l}$ of each of 3 diluted PCR products pooled together (Table 2) into $10 \mu \mathrm{l}$ of formamide (Applied Biosystems ${ }^{\mathrm{TM}}$ ) and $0.2 \mu \mathrm{l}$ of a 50 to $500 \mathrm{bp}$ size standard (GeneScan ${ }^{\mathrm{TM}}-500$ LIZ $\left.^{\mathrm{TM}}\right)$ in order to score microsatellite alleles on the Genetic Analyzer. Microsatellite alleles were scored using GeneMapper ${ }^{\circledR}$ Software v. 4.0 (Applied Biosystems ${ }^{\mathrm{TM}}$ ).

\section{Data analysis}

\section{Cytochrome c oxydase subunit 1}

CO1 sequences of 639 bp were reconstructed using both direction sequences and aligned with the alignment function of GENEIOUS Pro 5.3.4 (Biomatters $\left.{ }^{\mathrm{TM}}\right)$. Haplotype $(h)$ and nucleotide $(\pi)$ diversity values were calculated for each location using ARLEQUIN v. 3.5.1.2 (Excoffier \& Lischer 2010). The most relevant substitution model was tested with jModelTest 
v.0.1.1 (Posada 2008). Among the models proposed by ARLEQUIN, the best model was either that of Tamura \& Nei (1993) according to Akaike's information criterion corrected for small sample sizes (AICc) or the Kimura 2-parameter model with the criterion BIC. Both models provided equivalent results, so only Tamura-Nei genetic distances were used in the presented analyses to estimate the nucleotide diversity.

The genetic structure of Platichthys flesus was investigated along the western European coast, from England to Portugal. Relationships among haplotypes were analysed in a parsimony network estimated with TCS v.1.12 (Clement et al. 2000) using the statistical parsimony procedure (Templeton et al. 1992, Crandall et al. 1994). Fisher's exact tests of population differentiation $\left(F_{\mathrm{ST}}\right)$ based on haplotype frequencies (Raymond \& Rousset 1995, Duran et al. 2004) were performed in ARLEQUIN to test the null hypothesis of random haplotype distribution among sampling locations. The significance of individual tests was tested by comparison with simulated distribution constructed from 10,000 random permutations of the original data matrix. ARLEQUIN was also used to calculate the pairwise genetic distances $\left(\Phi_{\mathrm{ST}}\right)$ according to the model of Tamura \& Nei (1993). The significance of the genetic distances was tested by 10,000 random permutations of the original data matrix. Corrections for multiple simultaneous tests were performed by calculating the q-value (using the R package QVALUE) of each test, which measures the minimum false discovery rate (FDR) that is incurred when calling that test significant (Storey 2002).

We performed a multidimensional scaling (MDS) analysis using the function Classical (metric) Multidimensional scaling (CMD scale) in the R (Ihaka \& Gentleman 1996) package stats, also known as principal coordinate analysis (Gower 1966) on linearised pairwise FST (FST /1 - FST) (Slatkin 1995) to assess whether any indications for group structure could be observed. Analyses of molecular variance (AMOVA; Excoffier et al. 1992) were also performed in ARLEQUIN on a linearised distance matrix to quantify the level of genetic 
differentiation among and within groups previously identified by MDS. We executed 16,000 permutations to guarantee having less than $1 \%$ difference with exact probability in $99 \%$ of cases (Guo \& Tompson 1992, Duran et al. 2004). In addition, to verify isolation by distance we tested the correlation between linearised pairwise distances and geographic distances between locations (measured as the shortest distance between 2 locations along the coastline) with a Mantel test (Mantel 1967) implemented in ARLEQUIN, and significance was tested by 10,000 permutations.

\section{Microsatellites}

Allele frequencies and the observed and expected heterozygosity values were calculated in GENETIX v. 4.04 (Belkhir et al. 1996-2004). $F_{\mathrm{ST}}$ (index of genetic differentiation) and single- and multilocus $F_{\text {IS }}$ (indicating heterozygote deficiency/excess) were estimated (Weir \& Cockerham 1984) using GENETIX v. 4.04. Deviation from the Hardy-Weinberg equilibrium (HWE; Fisher's exact test) and gametic disequilibrium (Fisher's exact test) among loci were tested using GENEPOP v.4 (Raymond \& Rousset 1995, Rousset 2008). Both tests were corrected for multiple simultaneous tests by calculating the q-value of each test (Moran 2003). The bootstrap method was chosen as recommended by Storey (2002) for a limited number of $p$ values. The $q$ values were calculated using the R package QVALUE (www.r-project.org/, Storey 2002). Null allele frequencies were calculated based on Brookfield (1996) using the program MICRO-CHECKER (Van Oosterhout et al. 2004). Allele frequencies were then used to calculate pairwise genetic distances $D_{C}$ (Cavalli-Sforza \& Edwards 1967) using GENETIX v. 4.04. The significance of the genetic distances was tested by 10,000 permutations of individuals between populations. Correlation of genetic over geographical distances (measured as the shortest distance between 2 locations along the coastline) for all pairs of populations was tested with the Mantel permutation procedure 
available in GENETIX v. 4.04. To assess whether any indications for group structure could be observed, we performed an MDS analysis on the linearised pairwise genetic distances (Gower 1966).

\section{AMP deaminase}

Full sequences of the fragment of AMPD1 exon 1 were reconstructed using both direction sequences and then aligned with GENEIOUS Pro 5.3.4. As for microsatellites, allele frequencies and the observed and expected heterozygosity values were calculated in GENETIX v. 4.04; deviation from HWE (Fisher's exact test) and gametic disequilibrium (Fisher's exact test) among loci were tested using GENEPOP v. 4. Both tests were corrected for multiple simultaneous tests by calculating the $q$ value of each test, which measures the minimum FDR as explained for the CO1 data. Allele frequencies were then used to calculate pairwise genetic distances $D_{C}$ (Cavalli-Sforza \& Edwards 1967) using GENETIX v. 4.04 (Belkhir et al. 1996-2004). The significance of the genetic distances was tested by 10,000 permutations of individuals between populations. Isolation by distance was tested with the Mantel test, as described for the microsatellite data.

\section{Results}

\section{CO1}

\section{Genetic diversity within populations}

We obtained 639 bp sequences of CO1 corresponding to 21 groups identified by HRM analysis stemming from the 5 populations (Tamar, Canche, Seine, Vilaine, Mondego). Among the 21 individuals, we found a total of 4 haplotypes (CO1-Pf01, CO1-Pf02, CO1-Pf03, CO1Pf04), indicating a small degree of polymorphism. The sequences have been deposited in the GenBank Data Base (accession numbers JN859191, JN859192, JN859193, JN859194).We 
found a total of 3 polymorphic sites, but all mutations resulted in synonymous substitutions (Fig. 2). The statistical parsimony procedure produced a 'star-like' network; the most frequent haplotype was located in the central position of the network and was surrounded by lowfrequency haplotypes displaying a divergence of 1 mutation. Two common haplotypes were found in each location, and 1 private haplotype was found in Vilaine (Fig. 3).

Numbers of analysed individuals $(n)$, haplotypes $\left(N_{h}\right)$ and polymorphic sites $\left(N_{p}\right)$, and haplotype diversity $(h)$ and nucleotide diversity $(\pi)$ values per location are given in Table 3 . The haplotype diversity appeared moderate and did not display a latitudinal pattern over the data set, ranging from 0.375 to 0.508 , whereas the nucleotide diversity was globally low, but higher in the northern populations (Tamar and Canche: $\pi=0.0008$ ) compared to the other populations $(\pi=0.0006)$.

\section{Genetic structure}

The pairwise genetic comparisons $\left(\mathrm{F}_{\mathrm{ST}}\right)$ revealed limited differentiation (Table 4$)$ involving several pairs of populations (Tamar/Canche; Tamar/Vilaine; Vilaine/Mondego); however, these differentiations were non-significant. A pair of populations (Tamar/Seine) showed a significant differentiation confirmed by the exact tests based on p-values; this trend was not confirmed after the correction for multiple tests (Table 4).

The MDS analysis stressed the relative isolation of the Tamar population from the other populations (Fig. 4). The analysis of the distribution of the genetic variability between the Tamar and the group of 4 other populations, performed with an AMOVA, explained $2.95 \%$ of the total genetic variance in Platichthys flesus $\left(F_{\mathrm{CT}}=0.029, \mathrm{p}=0.24\right)$, confirming the reduced genetic structure over the data set.

The Mantel test revealed a lack of correlation between geographic distances and pairwise Slatkin's linearised F $F_{\text {ST }}$ values $(r=-0.48, \mathrm{p}=0.84)$. 


\section{Microsatellites}

\section{Genetic diversity within populations}

The microsatellite variability of Platichthys flesus appeared to be heterogeneous, with the total number of alleles per locus ranging from 7 (PFSCU3) to 35 (STPFL001) and the mean observed heterozygosity per locus varying between 0.384 (PFSCU3) and 0.765 (STPFL004) (Table 5). For each locus, the genetic diversity observed within samples was of the same magnitude over the whole data set.

Of the 8 microsatellites screened, 5 (STPFL001, PFSCU3, PFSCU4, STPFL025 and PFSCU7) exhibited substantial departures from HWE for 1 or 2 locations (Table 5). The mean allelic richness appeared higher in the northern estuaries Tamar and Canche $(8.87<\mathrm{r}<$ 9.12) relative to the other populations $(7.5<\mathrm{r}<8.3)$. The mean observed heterozygosity $\left(H_{\mathrm{o}}\right)$ was similar in the 5 estuaries $\left(0.62<H_{\mathrm{o}}<0.67\right)$. The multilocus statistics (Table 5) detected no significant deviation from HWE, regardless of the considered estuary (multilocus $F_{\mathrm{IS}}=0$ ). The software MICRO-CHECKER did not detect a significant departure from HWE linked to null alleles.

\section{Genetic structure}

The estimation of $F_{\mathrm{ST}}$ showed a significant multilocus differentiation over the entire data set $(\theta=0.010, p<0.05)$, confirmed by the multi-locus exact test of genetic differentiation ( $p=0.010 ;$ Table 6). The loci STPFL001, PFSCU3, PFSCU 4, PFSCU7, PFSCU 1 and STPFL004 displayed a significant global genetic differentiation between the populations, confirmed after the correction for multiple tests (Table 6).

Pairwise estimations of $F_{\mathrm{ST}}$ showed a significant differentiation mainly between Mondego and the other estuaries, and between Vilaine and Canche (Table 7). Over the 10 pairs of 
populations considered, 8 pairs displayed a significant genetic differentiation, confirmed after the correction for multiple tests.

The MDS analysis confirmed the isolation of Mondego from a group of northern estuaries and stressed the particular genetic status of the Seine within this group (Fig. 5). Finally, the Mantel test highlighted a significant correlation between geographical distances and linearised $\theta(Z=688.695 ; p=0.04)$, suggesting an isolation by distance of flounder populations throughout the coastal European waters.

\section{AMPD1}

Allele sequencing

First, 25 HRM variants were detected among the whole data set. After sequencing of the previous 25 HRM variants, we obtained 5 real genetic variants (AMPD1-Pf01; AMPD1-Pf02; AMPD1-Pf03; AMPD1-Pf04; AMPD1-Pf05, Appendix 1). We detected 2 polymorphic sites in positions 33 and 96 in the 160 bp sequences (5'3'). Mutations were all identified as synonymous, except for allele 1 detected in locus 96, which displayed a polymorphism resulting in a modification of the corresponding amino acid (Fig. 6).

\section{Genetic diversity within populations}

Regardless of the locus considered, 2 alleles were detected per locus and per location (Table 8). $H_{\mathrm{o}}$ was quite variable between the different populations $\left(0.31<H_{\mathrm{o}}<0.60\right.$ for locus 96 where Seine $>$ Tamar $>$ Mondego $>$ Vilaine $>$ Canche; $0.12<H_{\mathrm{o}}<0.25$ for locus 33 where Vilaine $>$ Canche $>$ Seine $>$ Mondego $>$ Tamar). The 2 loci showed substantial departures from HWE (Table 8). An exact test for gametic disequilibrium was performed and showed a link between the 2 loci $(\mathrm{p}=0.03)$, located on the same exon and separated by $63 \mathrm{bp}$. 


\section{Genetic structure}

Weir \& Cockerham's $\theta$ showed a significant global multi-locus genetic differentiation over the entire data set $(\theta=0.021, \mathrm{p}<0.05)$, confirmed by the exact test of genetic differentiation $(\mathrm{p}=0.018$; Table 9). Considered individually, locus 96 showed a significant global $\theta$ value of 0.033 confirmed by the exact test $(\mathrm{p}=0.004)$ which remained significant after $\mathrm{q}$ value correction. On the other hand, no significant differentiation over the whole data set was detected for locus 33 (Table 9).

The following analyses of genetic differentiation were carried out considering only locus 96, because this explained the whole differentiation between populations. Pairwise Weir \& Cockerham's $\theta$ underlined some significant genetic structure (Table 10), with the Seine estuary being significantly differentiated from the Canche, Vilaine and Mondego estuaries. The previous pattern was confirmed by the exact pairwise test of genetic differentiation and remained significant after q-value correction (Table 10). The MDS analysis confirmed the particular genetic status of the Seine compared to a group of estuaries composed of the Vilaine, Canche and Mondego; the Tamar estuary was located between the Seine and the previous group (Fig. 7). The Mantel test did not show any correlation with geographical distances $(Z=30806.543, p>0.05)$.

\section{Discussion}

\section{Phylogeography of Platichthys flesus}

The mtDNA loci are generally considered appropriate markers for inferring historical processes, thus allowing researchers to explore the phylogeography of numerous marine species widely distributed along the European coasts (Gysels et al. 2004, Roman \& Palumbi 2004, Larmuseau et al. 2010). In this study on Platichthys flesus, the analysis of mtDNA sequences identified from England to Portugal revealed (1) moderate haplotype diversity and 
reduced nucleotide diversity over the whole data set, and (2) 'star-like'-haplotype networks. This shallow population genetic architecture has classically been observed for numerous fish species with respect to mtDNA markers, and is probably linked to catastrophic reductions in population size or local extinctions during the Pleistocene glaciation, followed by a postglacial range expansion (Grant \& Waples 2000).

Furthermore, in this study, (1) the nucleotide diversity of the flounder was moderately higher for the northern populations (Tamar, Canche) compared to the southern group (Seine, Vilaine, Mondego), and (2) genetic differentiation between populations was very reduced, confirming previous results obtained on flounder mtDNA in the same area (Borsa et al. 1997); however, we observed a relative isolation of the Tamar estuary compared to the other sites.

The second type of genetic marker used in this work (microsatellites) can also be useful for phylogeographic studies and particularly for inferences on history of populations and possible founder events. Thus in this work, we confirmed higher genetic diversity for the Tamar and Canche compared to other populations, considering the allelic richness of microsatellites. A convergent result was obtained by Hemmer-Hansen et al. (2007a), who detected higher flounder microsatellite diversity in the North Sea and declining diversity in the extreme parts of the sampling area.

In the phylogeography of European marine fishes, it is commonly accepted that the British and Irish ice sheet extended to around $52^{\circ} \mathrm{N}$ at the time of the last glacial maximum (LGM: 22,000 $\mathrm{yr} \mathrm{BP}$ ), and that possible refugia were located in the southern North Sea and alongside unglaciated regions of the southern British Isles (Finnegan 2009). We suggest that the southern British Isles were major refugia for flounder during the LGM and thus could explain the higher genetic variability detected in the Tamar and Canche in terms of mtDNA and microsatellites. During the deglaciation period, the colonization of new habitats towards the 
north and south could be associated with founder events, and thus could have led to reduced genetic variability.

\section{Genetic structure of Platichthys flesus populations}

The microsatellites used in this study are generally considered as neutral markers subjected to high mutation rates, and thus are more appropriate than mtDNA for investigating recent events which contributed particularly to the genetic divergence of populations during the postglacial period (Grant \& Waples 2000).

In the present study, a low number of significant deficits of heterozygotes was observed for particular microsatellite loci. The problem of a heterozygote deficit for microsatellite loci is well documented in marine fish (O’Connell \& Wright 1997, Karlsson \& Mork 2005). Although factors such as inbreeding, the Wahlund effect, homoplasy or selection can explain deficits, they are frequently linked to an artifact of the PCR amplification process, i.e. to the presence of null alleles. The software MICRO-CHECKER was tested on the flounder data set and did not detect a significant departure from HWE linked to null alleles. Furthermore, in this study, the flounder populations were considered to be at HWE, thus reflecting the equilibrium between migration versus drift, classically observed for neutral markers.

The genetic variability (multilocus allelic richness and heterozygosity) was identical in the southern flounder populations of the data set (Seine, Vilaine, Mondego). Thus, genetic variability of the population was apparently maintained at the southern limit of the distribution area for the flounder (the Mondego estuary in Portugal). The flounder was clearly affected by global warming over the European coasts, thus for the period 1978 to 1997, clear changes were detected in the density of Platichthys flesus, which decreased in the Tagus estuary and, in contrast, increased in the northern Elbe estuary (Thiel et al. 2003); furthermore, the abundance of flounder has decreased to extremely rare since the early 1990s 
in the Tagus, and its distribution in Portugal is now limited to the north and central coasts (Cabral et al. 2001, 2007). The Mondego estuary is located $150 \mathrm{~km}$ north of the Tagus and, at the moment, probably harbours one of the most southern functional flounder populations in Europe.

In a review on the clinal patterns of genetic variation across species ranges, Hardie \& Hutchings (2010) showed that most studies are consistent with the general perception that peripheral populations are less genetically variable than those inhabiting central areas; this decrease is particularly associated with stochastic processes (founder effects, genetic drift, isolation and/or low gene flow) which occur in marine and freshwater environments.

We suggest that the current maintenance of the genetic diversity of flounder in the Mondego could be linked to the absence of frequent demographic bottlenecks in this population and thus to a limited possibility of genetic drift or inbreeding leading to a loss of genetic variability. Furthermore, the recent rarefaction of the flounder along the coast of Portugal, and the fact that the Mondego population could be related by gene flow to northern populations less exposed to thermal stress (Morais et al. 2011), could delay the potential impact of global warming on the demography and the genetic variability of this peripheral population.

Over the sampled area, from England to Portugal, we detected moderate but significant genetic differentiation between the populations, based on microsatellite variability $\left(F_{\mathrm{ST}}=0.01\right.$ with $\mathrm{p}<0.001)$. This level of genetic differentiation is comparable to that detected by Hemmer-Hansen et al. (2007a) for flounder from Norway to the Bay of Biscay; these authors occasionally observed higher levels of differentiation $\left(0.03<F_{\mathrm{ST}}<0.09\right)$, but only for comparisons involving the highly isolated populations of the data set (Faroe Islands, Lake Pulmanki) or populations reflecting particular adaptations to brackish environments (i.e. the benthic spawners in the inner Baltic Sea). Based on the pairwise exact test of genetic 
differentiation in our study, we confirmed that most of the differences were statistically significant, as previously shown by Hemmer-Hansen et al. (2007a) over northern populations. The genetic structure detected for the flounder is thus moderate but significant and robust over the whole distribution area. This differentiation between populations is probably related to the specificity of the flounder biological cycle, including (1) spawning at sea in moderate water depths $(20$ to $50 \mathrm{~m})$, sometimes at the mouth of the estuaries, (2) a trend towards homing back to the natal spawning site, and (3) a $2 \mathrm{yr}$ juvenile stage within the estuaries (Dando 2011) where diversifying selection can operate in various environmental contexts. On the other hand, the genetic structure of a species phylogenetically close to the flounder, the plaice Pleuronectes platessa, appeared very reduced over the same area (from Norway to the Bay of Biscay), with no differentiation detected between the Irish Sea, the Baltic Sea and the majority of the North Sea samples (Was et al. 2010); this result is mainly related to the less pronounced links of the plaice to estuarine systems and possibly to a lack of natal homing.

This study on flounder genetics was conducted in the south of the distribution area and underlines the particular genetic status of the southern population: the Mondego (pairwise differentiation involving Mondego: $\left.0.014<F_{\mathrm{ST}}<0.027\right)$. Geographical distance is probably not a major structuring factor for the flounder populations, as the Mantel test was significant over the whole data set, but became non-significant among the subset of samples excluding the Mondego. Our results agree with those of Hemmer-Hansen et al. (2007a) for the flounder where the geographical distance was significantly associated with genetic distances but was lost when corrected for latitudinal differences between samples.

We suggest that the flounder's strict links with estuaries or freshwaters at the juvenile stage, its limited average annual migration distance $(<32 \mathrm{~km}$, Summers 1979) and its reduced ability to migrate over deep seas (Aro 1989) could be the major factors structuring populations over the distribution area. Between England and Portugal, a major break in 
flounder habitat could be suggested in the southern Bay of Biscay linked to (1) the Capbreton canyon (Gonthier et al. 2006) and (2) the limited capacity of the Basque Country estuaries as nursery areas. Furthermore, a significant increase in the sea surface temperature in the southern Bay of Biscay for the period 1972 to 1993 (Désaunay et al. 2006), leading to a severe reduction in the abundance of flounder in this zone (Hermant et al. 2010), could contribute to the reduction in gene flow between the Bay of Biscay and Portugal.

\section{Possible selective pressure on flounder populations}

In this study, we considered the characterization of a partial genomic sequence of the white muscle AMPD in Platichthys flesus, revealing a high degree of conservation of both sequence and structural organization in comparison to the sequence of Rattus norvegicus (Thébault et al. 2010). We explored the polymorphism of exon 1 (160 bp) of the AMPD1 which codes for an important energy-related enzyme, involved in the stabilization of the adenylate energy charge. We detected 2 single nucleotide polymorphisms on the AMPD1 exon in positions 33 and 96, with each locus displaying 2 alleles shared by the different populations.

Contrasting levels of heterozygosity were detected for locus 96 in the whole data set; heterozygosity varied from 0.60 to 0.31 , with the following classification: Seine > Tamar > Mondego > Vilaine > Canche. We observed that the first 4 estuaries displayed an excess of heterozygotes, whereas the Canche was at HWE. The previous ranking of the estuaries could be linked to a decreasing gradient of contamination. The Seine experiences diffuse contamination similar to that reported in heavily polluted estuaries of North America (Munschy et al. 1997), and the Tamar displays high metal contamination linked to ancient mining activities (Pulsford et al. 1992). The Mondego and the Vilaine estuaries show moderate levels of organic chemicals (polychlorinated biphenyls and polycyclic aromatic hydrocarbons), and seasonal high level of pesticides as a result of intensive agriculture 
(Evrard et al. 2010, França et al. 2011). The Canche estuary is considered to be a pristine system, characterized by low levels of organic and metal pollutants (Amara et al. 2007). We suggest that this increasing heterozygosity for locus 96 in the flounder populations, following the contamination gradient, could be the result of selective pressure induced by the contaminants on this locus or on a linked locus. Contrasting levels of heterozygosity were also detected in flounder populations for locus $33(0.12<$ Ho $<0.25)$, although we are unable to formulate a hypothesis on the observed population ranking: Vilaine > Canche > Seine > Mondego > Tamar.

A significant multilocus level of genetic differentiation was detected in the whole data set. A significant linkage disequilibrium was observed between the 2 loci, and thus we analysed the genetic structure linked to locus 96 which mainly contributed to the genetic structure; the differentiation linked to locus 33 was not significant. Significant and relatively high values of genetic differentiation were observed based on the pairwise estimations involving the Seine estuary $\left(0.015<F_{\mathrm{ST}}<0.101\right)$. The MDS diagram showed growing genetic distances between the following pairs of populations, Seine/Tamar, Seine/Mondego and Seine/Vilaine-Canche, confirming the population ranks based on the heterozygosity of locus 96 .

Finally, over the whole data set, we observed discordant patterns of variation considering the candidate gene, the AMPD1 locus 96 and the neutral markers (microsatellites). These results could indicate that selective forces have shaped the genetic population structure by given the polymorphism of the AMPD1, the genetic structure explained by the microsatellites being suggestive of stochastic forces (founder effects, migration and genetic drift). In fact, we suggest that the genetic differentiation of AMPD1 locus 96 potentially reflects the existence of cocktails of pollutants acting as selective agents in chronically contaminated populations in estuaries; we propose the hypothesis of a possible 'resistant character' associated with the heterozygosity of this locus in contaminated systems. The polymorphism observed at locus 96 
showed different mutations, with 1 mutation leading to an amino acid change; we suggest that the selective pressure could act directly on this locus or indirectly through the hitch-hiking phenomenon.

This study confirms previous work showing that selective pressure of contrasting environments (variable levels of contaminants, reduced salinities, more or less chronic hypoxia, highly variable temperature) could potentially induce adaptive responses of the flounder populations (Marchand et al. 2004, 2010, Hemmer-Hansen et al. 2007b). However, the hypothesis of selective pressure induced by the contaminants and acting on locus AMPD1 should be confirmed in the near future, considering genotype-phenotype couplings in the field; such explorations were conducted in the past on flounder populations where differential tolerances to chemical stress were detected among genotypes (Marchand et al. 2004).

\section{Perspectives}

This study incorporating a phylogeographical framework and a population genetics approach based on neutral markers and a candidate gene confirms that the European flounder is probably an excellent candidate species to explore the adaptive responses of fish populations facing climate change and anthropogenic stressors in southern Europe.

Genetic monitoring of southern fish populations directly subjected to global warming must be conducted on a finer regional scale (Schwartz et al. 2007) and should explore how connectivity between populations could be altered by changes in ocean temperature (Kelly \& Eernisse 2007, O’Connor et al. 2007).

If the neutral genetic diversity appears not to be reduced at the moment in the southern flounder populations, surveys must be developed to monitor population abundance and contemporary effective population size for early detection of population declines in this area (Waples \& Do 2010, Antao et al. 2011). 
The analysis of the variability of several traits (e.g. gene expression, physiological responses and life history traits) across environmental clines should yield important information; in particular, common garden experiments can help to distinguish genetic responses (potentially adaptive) from environmental effects and phenotype plasticity (Larsen et al. 2007, Hardie \& Hutchings 2010). Thus, we are currently conducting a common garden experiment on flounder to explore the possibility that peripheral populations compared to core populations may be differentially adapted for survival in harsh environments.

\section{Acknowledgements}

We thank N. Quéré for excellent technical assistance. This work was financed by the ANR programme VMCS-EVOLFISH (Paris) and by the EEC programme INTERREG IV-DIESE. Sequencing was conducted at the Molecular Laboratory of the Biodiversity and Climate Research Centre (BiK-F) based on financial support of the research funding programme 'LOEWE - Landes-Offensive zur Entwicklung Wissenschaftlich-ökonomischer Exzellenz' of Hesse's Ministry of Higher Education, Research and the Arts. 


\section{Literature cited}

Amara R, Meziane T, Gilliers C, Hermel G, Laffargue P (2007) Growth and condition indices in juvenile sole Solea solea measured to assess the quality of essential fish habitat. Mar Ecol Prog Ser 351:201-208. DOI: 10.3354/meps07154

Antao T, Pérez-Figueroa A, Luikart G (2011) Early detection of population declines: high power of genetic monitoring using effective population size estimators. Evol Appl 4:144154. DOI: $10.1111 / \mathrm{j} .1752-4571.2010 .00150 . \mathrm{x}$

Aro E (1989) A review of fish migration patterns in the Baltic. Rapp P-V Cons Int Explor Mer 190:72-96

Avise JC (1994) Molecular markers, natural history and evolution. Chapman and Hall, New York, NY

Ballard JWO, Melvin RG (2010) Linking the mitochondrial genotype to the organismal phenotype. Mol Ecol 19:1523-1539. DOI: 10.1111/j.1365-294X.2010.04594.x

Belkhir K, Borsa P, Chikhi L, Raufaste N, Bonhomme F (1996-2004) GENETIX 4.05, logiciel sous Windows TM pour la génétique des populations. Laboratoire Génome, Populations, Interactions, Université de Montpellier II, Montpellier

Borsa P, Blanquer A, Berrebi P (1997) Genetic structure of the flounders Platichthys flesus and P. stellatus at different geographic scales. Mar Biol 129:233-246.

DOI: $10.1007 / \mathrm{s} 002270050164$

Brookfield JFY (1996) A simple new method for estimating null allele frequency from heterozygote deficiency. Mol Ecol 5:453-455.

Cabral HN, Costa MJ, Salgado JP (2001) Does the Tagus estuary fish community reflect environmental changes? Clim Res 18:119-126. DOI: 10.3354/cr018119 
Cabral HN, Vasconcelos R, Vinagre C, França S and others (2007) Relative importance of estuarine flatfish nurseries along the Portuguese coast. J Sea Res 57:209-217.

DOI: 10.1016/j.seares.2006.08.007

Cachot J, Geffard O, Augagneur S, Lacroix S and others (2006) Evidence of genotoxicity related to high $\mathrm{PAH}$ content of sediments in the upper part of the Seine estuary (Normandy, France). Aquat Toxicol 79:257-267. DOI: 10.1016/j.aquatox.2006.06.014

Casas P, Martinez P, Sanchez L (2005) Characterization of microsatellite markers derived from sequence databases for the European flounder (Platichthys flesus). Mol Ecol Notes 5:664-665. DOI: 10.1111/j.1471-8286.2005.01036.x

Cavalli-Sforza LL, Edwards AWF (1967) Phylogenetic analysis: models and estimation procedures. Evolution 21:550-570. DOI: 10.2307/2406616

Chang EH, Menezes M, Meyer NC, Cucci RA, Vervoort VS, Schwartz CE, Smith RJH (2004) Branchio-oto-renal syndrome: the mutation spectrum in EYA1 and its phenotypic consequences. Hum Mutat 23:582-589. DOI: 10.1002/humu.20048

Chapman AG, Atkinson DE (1973) Stabilization of adenylate energy charge by the adenylate reaction. J Biol Chem 248:8309-8312 .

Clement M, Posada D, Crandall KA (2000) TCS: a computer program to estimate gene genealogies. Mol Ecol 9:1657-1659.

Crandall KA, Templeton AR, Sing CF (1994) Intraspecific phylogenetics: problems and solutions. In: Scotland RW, Siebert DJ, Williams DM (eds) Models in phylogeny reconstruction. Systematics Association Special Vol 52. Clarendon Press, Oxford, p 273297.

Dando PR (2011) Site fidelity, homing and spawning migrations of flounder Platichthys flesus in the Tamar estuary, South West England. Mar Ecol Prog Ser 430:183-196.

DOI: $10.3354 /$ meps09116 
Désaunay Y, Guérault D, Le Pape O, Poulard JC (2006) Changes in occurrence and abundance of northern/southern flatfishes over a 20 -year period in a coastal nursery area (Bay of Vilaine) and on the eastern continental shelf of the Bay of Biscay. Sci Mar 70(Suppl1):193-200.

Dixon TJ (2003) Molecular genetic studies of pollutant response in the European flounder, Platichthys flesus (L.). PhD thesis, University of Stirling.

Duran S, Palacin C, Becerro MA, Turon X, Giribet G (2004) Genetic diversity and population structure of the commercially harvested sea urchin Paracentrotus lividus (Echinodermata, Echinoidea). Mol Ecol 13:3317-3328. DOI: 10.1111/j.1365-294X.2004.02338.x

Evrard E, Devaux A, Bony S, Burgeot T and others (2010) Responses of the European flounder Platichthys flesus to the chemical stress in estuaries: load of contaminants, gene expression, cellular impact and growth rate. Biomarkers 15:111-127.

DOI: $10.3109 / 13547500903315598$

Excoffier L, Lischer HEL (2010) Arlequin suite ver 3.5: a new series of programs to perform population genetics analyses under Linux and Windows. Mol Ecol Resour 10:564-567. DOI: $10.1111 / \mathrm{j} .1755-0998.2010 .02847 . x$

Excoffier L., Smouse P, Quattro J (1992) Analysis of molecular variance inferred from metric distances among DNA haplotypes: Application to human mitochondrial DNA restriction data. Genetics 131:479-491.

Finnegan AK (2009) The genetic structuring of Atlantic salmon (Salmo salar) populations in northwest Europe as revealed through nuclear microsatellite and mtDNA PCR-RFLP analysis: from regional to catchment level analysis and its application in conservation and management of the species. $\mathrm{PhD}$ thesis, University of Exeter.

Forget J (1998) Impact neurotoxique de contaminants (pesticides et métaux) sur un crustacé marin Tigriopus brevicornis (Muller). Caractérisation de la cholinestérase et application à 
la surveillance des effets des polluants sur l'environnement marin. $\mathrm{PhD}$ thesis, Université de Paris VI.

França S, Costa MJ, Cabral HN (2011) Inter- and intra-estuarine fish assemblage variability patterns along the Portuguese coast. Estuar Coast Shelf Sci 91:262-271.

DOI: $10.1016 /$ j.ecss.2010.10.035

Gilliers C (2004) Recherche d'indicateurs de la qualité des écosystèmes côtiers: application aux nourriceries côtières et estuariennes des poissons plats. $\mathrm{PhD}$ thesis, Université du Littoral-Côte d'Opale, Dunkerque.

Gonthier E, Cirac P, Faugeres JC, Gaudin M, Cremer M, Bourillet JF (2006) Instabilities and deformation in the sedimentary cover on the upper slope of the southern Aquitaine continental margin, north of the Capbreton canyon (Bay of Biscay). Sci Mar 70(Suppl 1):89-100.

Gower JC (1966) Some distance properties of latent root and vector methods used in multivariate analysis. Biometrika 53:225-228.

Grant WS, Waples RS (2000) Spatial and temporal scales of genetic variability in marine and anadromous species: implications for fisheries oceanography. In: Harrison PJ, Parsons TR (eds) Fisheries oceanography: an integrative approach to fisheries ecology and management. Fish Aquat Res Ser 4. Blackwell Science, Oxford, p 61-93.

Guo SW, Tompson EA (1992) Performing the exact test of Hardy-Weinberg proportion for multiple alleles. Biometrics 48:361-372. DOI: 10.2307/2532296

Gysels ES, Hellemans B, Pampoulie C, Volckaert FAM (2004) Phylogeography of the common goby, Pomatoschistus microps, with particular emphasis on the colonization of the Mediterranean and the North Sea. Mol Ecol 13:403-417.

DOI: 10.1046/j.1365-294X.2003.02087.x 
Hardie DC, Hutchings JA (2010) Evolutionary ecology at the extremes of species ranges. Environ Rev 18:1-20. DOI: 10.1139/A09-014

Harley CDG, Hughes AR, Hultgren KM, Miner BG and others (2006) The impacts of climate change in coastal marine systems. Ecol Lett 9:228-241.

DOI: $10.1111 / \mathrm{j} .1461-0248.2005 .00871 . \mathrm{x}$

Hemmer-Hansen J, Nielsen EE, Gronkjaer P, Loeschcke V (2007a) Evolutionary mechanisms shaping the genetic population structure of marine fishes; lessons from the European flounder (Platichthys flesus L.). Mol Ecol 16:3104-3118.

DOI: $10.1111 /$ j.1365-294X.2007.03367.x

Hemmer-Hansen J, Nielsen EE, Frydenberg J, Loeschcke V (2007b) Adaptive divergence in a high gene flow environment: Hsc70 variation in the European flounder (Platichthys flesus L.). Heredity 99:592-600. DOI: 10.1038/sj.hdy.6801055

Hermant M, Lobry J, Bonhommeau S, Poulard JC, Le Pape O (2010) Impact of warming on abundance and occurrence of flatfish populations in the Bay of Biscay (France). J Sea Res 64:45-53. DOI: 10.1016/j.seares.2009.07.001

Hutchings JA, Swain DP, Rowe S, Eddington JD, Puvanendran V, Brown JA (2007) Genetic variation in life-history reaction norms in a marine fish. Proc R Soc Lond B Biol Sci 274:1693-1699. DOI: 10.1098/rspb.2007.0263

Ihaka R, Gentleman R (1996) R: a language for data analysis and graphics. J Comput Graph Statist 5:299-314.

Ivanova NV, de Waard J, Hebert PDN (2006) An inexpensive, automation-friendly protocol for recovering high-quality DNA. Mol Ecol Notes 6:998-1002.

DOI: $10.1111 / j .1471-8286.2006 .01428 . x$ 
Karlsson S, Mork J (2005) Deviations from Hardy-Weinberg equilibrium, and temporal instability in allele frequencies at microsatellite loci in a local population of Atlantic cod. ICES J Mar Sci 62:1588-1596. DOI: 10.1016/j.icesjms.2005.05.009

Kelly RP, Eernisse DJ (2007) Southern hospitality: a latitudinal gradient in gene flow in the marine environment. Evolution 61:700-707. DOI: 10.1111/j.1558-5646.2007.00055.x

Larmuseau MHD, Raeymaekers JAM, Hellemans H, Van Houdt JKJ, Volckaert FAM (2010) Mito-nuclear discordance in the degree of population differentiation in a marine goby. Heredity 105:532-542. DOI: 10.1038/hdy.2010.9

Larsen PF, Nielsen EE, Williams TD, Hemmer-Hansen J and others (2007) Adaptive differences in gene expression in European flounder (Platichthys flesus). Mol Ecol 16:4674-4683. DOI: 10.1111/j.1365-294X.2007.03530.x

Lowenstein JM (1972) Ammonia production in muscle and other tissues: the purine nucleotide cycle. Physiol Rev 52:382-414.

Mantel N (1967) The detection of disease clustering and a generalized regression approach. Cancer Res 27:209-220.

Marchand J, Tanguy A, Laroche J, Quiniou L, Moraga D (2003) Responses of European flounder Platichthys flesus populations to contamination in different estuaries along the Atlantic coast of France. Mar Ecol Prog Ser 260:273-284. DOI: 10.3354/meps260273

Marchand J, Quiniou L, Riso R, Thébaut MT, Laroche J (2004) Physiological cost of tolerance to toxicants in the European flounder Platichthys flesus, along the French Atlantic coast. Aquat Toxicol 70:327-343. DOI: 10.1016/j.aquatox.2004.10.001

Marchand J, Evrard E, Guinand B, Cachot J, Quiniou L, Laroche J (2010) Genetic polymorphism and its potential relation to environmental stress in five populations of the European flounder Platichthys flesus, along the French Atlantic coast. Mar Environ Res 70:201-209. DOI: 10.1016/j.marenvres.2010.05.002 
Meistertzheim AL, Calves I, Artigaud S, Friedman CS, Laroche J, Paillard C, Ferec C (2012) High Resolution Melting Analysis for fast and cheap polymorphism screening of marine populations. Protocol Exchange. DOI 10.1038/protex.2012.015

Menesguen A, Aminot A, Belin C, Chapelle A and others (2001) L'eutrophisation des eaux marines et saumâtres en Europe en particulier en France. Rapport IFREMER pour la Commission Européenne - DG. ENV. B1. IFREMER, Plouzané.

Morais P, Dias E, Babaluk J, Antunes C (2011) The migration patterns of the European flounder Platichthys flesus (Linnaeus, 1758) (Pleuronectidae, Pisces) at the southern limit of its distribution range: ecological implications and fishery management. J Sea Res 65:235-246. DOI: 10.1016/j.seares.2010.11.001

Moran MD (2003) Arguments for rejecting the sequential Bonferroni in ecological studies. Oikos 100:403-405. DOI: 10.1034/j.1600-0706.2003.12010.x

Munschy C, Mosan K, Truquet I, Tronczynski J (1997) Caractérisation chimique de la contamination organique dans l'estuaire de la Seine. Rapport Seine-Aval 1996. Agence de l'Eau Seine-Normandie, Nanterre.

Nielsen EE, Nielsen PH, Meldrup D, Hansen MM (2004) Genetic population structure of turbot (Scophthalmus maximus L.) supports the presence of multiple hybrid zones for marine fishes in the transition zone between the Baltic Sea and the North Sea. Mol Ecol 13:585-595. DOI: 10.1046/j.1365-294X.2004.02097.x

O’Connell M, Wright JM (1997) Microsatellite DNA in fishes. Rev Fish Biol Fish 7:331-363. DOI: 10.1023/A:1018443912945

O’Connor MI, Bruno JF, Gaines SD, Halpern BS, Lester SE, Kinlan BP, Weiss JM (2007) Temperature control of larval dispersal and the implications for marine ecology, evolution, and conservation. Proc Natl Acad Sci USA 104:1266-1271.

DOI: $10.1073 /$ pnas.0603422104 
Olsen EM, Knutsen H, Gjosaeter J, Jorde PE, Knutsen JA, Stenseth NC (2008) Small-scale biocomplexity in coastal Atlantic cod supporting a Darwinian perspective on fisheries management. Evol Appl 1:524-533. DOI: 10.1111/j.1752-4571.2008.00024.x

Posada D (2008) jModelTest: phylogenetic model averaging. Mol Biol Evol 25:1253-1256. DOI: $10.1093 / \mathrm{molbev} / \mathrm{msn} 083$

Pulsford AI, Ryan KP, Nott JA (1992) Metals and melanomacrophages in flounder, Platichthys flesus, spleen and kidney. J Mar Biol Assoc UK 72:483-498.

DOI: $10.1017 / \mathrm{S} 002531540003784 \mathrm{X}$

Raymond M, Rousset F (1995) GENEPOP (version 1.2): population genetics software for exact tests and ecumenicism. J Hered 86:248-249.

Roman J, Palumbi SR (2004) A global invader at home: population structure of the green crab Carcinus maenas, in Europe. Mol Ecol 13:2891-2898.

DOI: $10.1111 / j .1365-294 X .2004 .02255 . x$

Rousset F (2008) Genepop'007: a complete reimplementation of the Genepop software for Windows and Linux. Mol Ecol Resour 8:103-106.

DOI: $10.1111 / j .1471-8286.2007 .01931 . x$

SAGE (Schéma d'aménagement et de gestion des eaux) Vilaine (1999) Projet de schéma d'aménagement et de gestion des eaux de la Vilaine Atlas. Institution d'Aménagement de la Vilaine La Roche Bernard. Available at: www.eptb-vilaine.fr/site/index.php/pres-sage.

Schuelke M (2000) An economic method for the fluorescent labeling of PCR fragments. Nat Biotechnol 18:233-234. DOI: 10.1038/72708

Schwartz MK, Luikart G, Waples RS (2007) Genetic monitoring as a promising tool for conservation and management. Trends Ecol Evol 22:25-33.

DOI: $10.1016 /$ j.tree.2006.08.009 
Sgro CM, Lowe AJ, Hoffmann AA (2011) Building evolutionary resilience for conserving biodiversity under climate change. Evol Appl 4:326-337.

DOI: $10.1111 / \mathrm{j} .1752-4571.2010 .00157 . \mathrm{x}$

Slatkin M (1995) A measure of population subdivision based on microsatellite allele frequencies. Genetics 139:457-462.

Storey JD (2002) A direct approach to false discovery rates. J R Stat Soc B Stat Methodol 64:479-498. DOI: 10.1111/1467-9868.00346

Summers RW (1979) Life cycle and population ecology of the flounder Platichthys flesus (L.) in the Ythan estuary, Scotland. J Nat Hist 13:703-723.

DOI: $10.1080 / 00222937900770531$

Tamura K, Nei M (1993) Estimation of the number of nucleotide substitutions in the control region of mitochondrial DNA in humans and chimpanzees. Mol Biol Evol 10:512-526.

Templeton AR, Crandall KA, Sing CF (1992) A cladistic analysis of phenotypic associations with haplotypes inferred from restriction endonuclease mapping and DNA sequence data. III. Cladogram estimation. Genetics 132:619-633.

Thébault MT, Tanguy A, Meistertzheim AL, Raffin JP (2010) Partial characterization of the gene encoding myoadenylate deaminase from the teleost fish Platichthys flesus. Fish Physiology and Biochemistry 36(4):819-825. DOI: 10.1007/s10695-009-9358-y.

Thiel R, Cabral H, Costa MJ (2003) Composition, temporal changes and ecological guild classification of the ichthyofaunas of large European estuaries - a comparison between the Tagus (Portugal) and the Elbe (Germany). J Appl Ichthyol 19:330-342.

DOI: 10.1046/j.1439-0426.2003.00474.x 
Tysklind N, Neuparth T, Ashcroft GR, Taylor MI, Lyons BP, McCarthy ID, Carvalho GR (2009) Isolation and characterization of 28 new microsatellite markers for European flounder (Platchithys flesus L.). Mol Ecol Resour 9:1065-1068.

DOI: 10.1111/j.1755-0998.2009.02589.x

Van Oosterhout C, Hutchinson WF, Wills DPM, Shipley P (2004) MICRO-CHECKER: software for identifying and correcting genotyping errors in microsatellite data. Mol Ecol Notes 4:535-538. DOI: 10.1111/j.1471-8286.2004.00684.x

Waples RS, Do C (2010) Linkage disequilibrium estimates of contemporary Ne using highly variable genetic markers: a largely untapped resource for applied conservation and evolution. Evol Appl 3:244-262. DOI: 10.1111/j.1752-4571.2009.00104.x

Ward RD, Zemlak TS, Innes BH, Last PR, Hebert PD (2005) DNA barcoding Australia's fish species. Philos Trans R Soc Lond B Biol Sci 360:1847-1857.

DOI: $10.1098 /$ rstb.2005.1716

Was A, Gosling E, Hoarau G (2010) Microsatellite analysis of plaice (Pleuronectes platessa L.) in the NE Atlantic: weak genetic structuring in a milieu of high gene flow. Mar Biol 157:447-462. DOI: 10.1007/s00227-009-1331-X

Weir BS, Cockerham CC (1984) Estimating F-statistics for the analysis of population structure. Evolution 38(6):1358-1370.

Yoshino M, Muramaki K (1981) In situ studies on AMP deaminase as a control of the adenylate energy charge in yeasts. Biochim Biophys Acta 672:16-20.

DOI: 10.1016/0304-4165(81)90274-9 
Table 1. Platichthys flesus. Fish sampling sites and number of individuals analysed for each genetic marker. CO1: cytochrome $c$ oxidase subunit 1, AMPD1: AMP-deaminase isoform 1

\begin{tabular}{lllll}
\hline Collection site & Sampling date & Microsatellites & CO1 & AMPD1 \\
\hline Tamar (England) & Nov 2009 & 43 & 44 & 41 \\
Seine (France) & Oct 2009 & 42 & 50 & 46 \\
Canche (France) & Nov 2009 & 48 & 50 & 46 \\
Vilaine (France) & Oct 2009 & 44 & 44 & 40 \\
Mondego (Portugal) & Sep 2009 & 47 & 46 & 48 \\
\hline
\end{tabular}

Table 2. Primer sequences and annealing temperatures for all primers used in the study

\begin{tabular}{|c|c|c|c|}
\hline Primer & Sequence & Annealing temp. $\left({ }^{\circ} \mathrm{C}\right)$ & Multiplex \\
\hline STPFL001_F & 5' CATCAAAGCATGAAACCC 3' & 54 to 49 & \multirow{6}{*}{ Multiplex 1} \\
\hline STPFL001_R & 5' CTGGCCCAAGTGGAGCAT 3' & 54 to 49 & \\
\hline PFSCU4_F & 5' TGGGCCGACGTGAAATAGT 3' & 54 to 49 & \\
\hline PFSCU4_R & 5' TGCTACTGGCTTTGTGATTT 3' & 54 to 49 & \\
\hline STPFL004_F & 5' ATGAGGACGTGGATGTTCTTC 3' & 54 to 49 & \\
\hline STPFL004_R & 5' CCCCTATCTCTGCTTAATGTTCAC 3' & 54 to 49 & \\
\hline PFSCU8_F & 5' ACCGCAGTTCATTGTTTGTG 3' & 54 to 49 & \multirow{6}{*}{ Multiplex 2} \\
\hline PFSCU8_R & 5' TTGGAGGGTTCCATTCTGTG 3' & 54 to 49 & \\
\hline PFSCU3_F & 5' CAGTGTAATGACCACACACCA 3' & 54 to 49 & \\
\hline PFSCU3_R & 5' CTGGACAAATAAGCATCCAAG 3' & 54 to 49 & \\
\hline STPFL025_F & 5' TTCAACAATGACCAAGGGGCATCA 3' & 54 to 49 & \\
\hline STPFL025_R & 5' TTTGCAATCTTGTAACACCTGAGA 3' & 54 to 49 & \\
\hline PFSCU1_F & 5' CTATCATGTCCCAGGGTGAA 3' & 54 to 49 & \multirow{4}{*}{ Multiplex 3} \\
\hline PFSCU1_R & 5' AGATGGAGGAGGTGGAGGAG 3' & 54 to 49 & \\
\hline PFSCU7_F & 5' GGCTCTACCCAACACCCATA 3' & 54 to 49 & \\
\hline PFSCU7_R & 5' CCATCACCTTGCTCTACTCAAG 3' & 54 to 49 & \\
\hline Universal 1 & 5' TCGGATAGCTAGTCGT 3' & 54 to 49 & \\
\hline Universal 2 & 5' CTGGCCGTCGTTTTAC 3' & 54 to 49 & \\
\hline Universal 3 & 5' TAGTCGACGACCGTTA 3' & 54 to 49 & \\
\hline Fish-F2 & 5' TCGACTAATCATAAAGATATCGGCAC 3' & 65 to 53 & \\
\hline Fish-R2 & 5' ACTTCAGGGTGACCGAAGAATCAGAA 3' & 65 to 53 & \\
\hline PfAMPD1_F & 5' ATGGACGACTTTGAGCTTCCTG 3' & 65 to 53 & \\
\hline PfAMPD1_R & 5' CACCСТTTCTCCTGACCTGG 3' & 65 to 53 & \\
\hline
\end{tabular}

Table 3. Platichthys flesus. Genetic diversity (cytochrome $c$ oxidase subunit 1, CO1) of the studied populations, showing sample size $(\mathrm{n})$, number of haplotypes $\left(N_{\mathrm{h}}\right)$, number of polymorphic sites $\left(N_{\mathrm{p}}\right)$, haplotype diversity $(h)$ and nucleotide diversity $(\square)$. Standard deviation is given in parentheses

\begin{tabular}{llllll}
\hline Population & $\mathbf{n}$ & $\boldsymbol{N h}$ & $\boldsymbol{N p}$ & $\boldsymbol{h}$ & $\boldsymbol{\pi}$ \\
\hline Tamar & 44 & 3 & 2 & $0.4683(0.0766)$ & $0.000802(0.000767)$ \\
Canche & 50 & 3 & 2 & $0.5086(0.0474)$ & $0.000843(0.000789)$ \\
Seine & 50 & 3 & 1 & $0.4286(0.0532)$ & $0.000673(0.000686)$ \\
Vilaine & 50 & 3 & 2 & $0.3754(0.0756)$ & $0.000605(0.000645)$ \\
Mondego & 50 & 3 & 2 & $0.4175(0.0685)$ & $0.000674(0.000688)$ \\
\hline
\end{tabular}


Table 4. Platichthys flesus. Genetic differentiation (cytochrome $c$ oxidase subunit 1, CO1) of the studied populations. Pairwise $F_{S T}$ (above diagonal) and p-values of the pairwise exact tests of population differentiation (below diagonal), *p $<\mathbf{0 . 0 5}$. p-values did not remain significant after q-value correction

\begin{tabular}{lrrrrr}
\hline & Tamar & Canche & Seine & Vilaine & Mondego \\
\hline Tamar & - & 0.035 & $0.035^{*}$ & 0.008 & 0.005 \\
Canche & 0.143 & - & -0.013 & 0.019 & -0.004 \\
Seine & 0.030 & 0.386 & - & 0.000 & -0.014 \\
Vilaine & 0.091 & 0.129 & 0.344 & - & -0.016 \\
Mondego & 0.225 & 0.559 & 0.567 & 0.801 & - \\
\hline
\end{tabular}

Table 5. Platichthys flesus. Genetic diversity (microsatellites) of the studied populations. Number of alleles $\left(N_{\mathrm{A}}\right)$, observed $\left(\mathrm{H}_{\mathrm{o}}\right)$ and unbiased $\left(\mathrm{H}_{\mathrm{e}}\right)$ heterozygosities and $F_{\text {IS }}$ for each location and each locus. $F_{\text {IS }}$ was estimated according to Weir \& Cockerham and was tested using the Markov chain method with 5,000 iterations $(* \mathbf{p}<0.05 ; * * * \mathbf{p}<0.001)$. Bold indicates $\boldsymbol{F}_{\text {IS }}$ values that remained significant after q-value correction

\begin{tabular}{|c|c|c|c|c|c|c|c|c|c|c|}
\hline \multirow{2}{*}{ Population } & & \multicolumn{8}{|l|}{ Locus } & \multirow[b]{2}{*}{ Multilocus } \\
\hline & & STPFL001 & PFSCU4 & PFSCU3 & STPFL025 & PFSCU7 & PFSCU1 & PFSCU8 & STPFL004 & \\
\hline \multirow[t]{4}{*}{ Tamar } & $N_{\mathrm{A}}$ & 20 & 5 & 3 & 4 & 7 & 14 & 6 & 26 & 9.1 \\
\hline & $\mathbf{H}_{\mathbf{o}}$ & 0.767 & 0.512 & 0.256 & 0.488 & 0.628 & 0.791 & 0.744 & 0.744 & 0.628 \\
\hline & $\mathbf{H}_{\mathbf{e}}$ & 0.86 & 0.524 & 0.268 & 0.505 & 0.746 & 0.772 & 0.667 & 0.732 & 0.616 \\
\hline & $\mathbf{F}_{\text {IS }}$ & +0.108 & +0.023 & +0.045 & +0.034 & $+0.160 *$ & -0.024 & -0.117 & -0.017 & 0.029 \\
\hline \multirow[t]{4}{*}{ Canche } & $N_{\mathrm{A}}$ & 17 & 4 & 3 & 7 & 7 & 13 & 7 & 27 & 8.875 \\
\hline & $\mathbf{H}_{\mathbf{o}}$ & 0.708 & 0.583 & 0.479 & 0.708 & 0.708 & 0.75 & 0.792 & 0.646 & 0.641 \\
\hline & $\mathbf{H}_{\mathbf{e}}$ & 0.823 & 0.52 & 0.381 & 0.602 & 0.668 & 0.768 & 0.708 & 0.712 & 0.671 \\
\hline & $\mathbf{F}_{\text {IS }}$ & $+0.141 *$ & -0.123 & $-0.260 * * *$ & $-0.179 *$ & -0.061 & +0.024 & -0.120 & +0.094 & -0.037 \\
\hline \multirow[t]{4}{*}{ Seine } & $N_{\mathrm{A}}$ & 16 & 3 & 4 & 5 & 7 & 12 & 4 & 20 & 7.9 \\
\hline & $\mathbf{H}_{\mathbf{o}}$ & 0.814 & 0.488 & 0.372 & 0.558 & 0.674 & 0.697 & 0.767 & 0.744 & 0.625 \\
\hline & $\mathrm{He}$ & 0.872 & 0.475 & 0.368 & 0.571 & 0.62 & 0.699 & 0.652 & 0.806 & 0.639 \\
\hline & $\mathbf{F}_{\text {IS }}$ & +0.067 & $-0.029 *$ & -0.026 & +0.023 & -0.088 & 0.002 & -0.180 & +0.078 & -0.010 \\
\hline \multirow[t]{4}{*}{ Vilaine } & $N_{\mathrm{A}}$ & 14 & 2 & 5 & 4 & 9 & 12 & 6 & 27 & 8.4 \\
\hline & Но & 0.795 & 0.682 & 0.364 & 0.568 & 0.613 & 0.75 & 0.545 & 0.841 & 0.638 \\
\hline & He & 0.813 & 0.505 & 0.355 & 0.515 & 0.714 & 0.754 & 0.672 & 0.836 & 0.644 \\
\hline & $\mathbf{F}_{\text {IS }}$ & +0.022 & -0.356 & -0.010 & -0.104 & $+0.142 *$ & +0.005 & +0.190 & -0.006 & 0.001 \\
\hline \multirow[t]{4}{*}{ Mondego } & $N_{\mathrm{A}}$ & 10 & 4 & 5 & 5 & 7 & 12 & 5 & 22 & 7.5 \\
\hline & $\mathbf{H}_{\mathbf{o}}$ & 0.681 & 0.489 & 0.447 & 0.596 & 0.723 & 0.745 & 0.681 & 0.851 & 0.645 \\
\hline & $\mathbf{H}_{\mathbf{e}}$ & 0.802 & 0.536 & 0.399 & 0.546 & 0.681 & 0.788 & 0.653 & 0.814 & 0.651 \\
\hline & $\mathbf{F}_{\text {IS }}$ & $+0.152 *$ & +0.088 & -0.120 & -0.091 & -0.064 & +0.055 & -0.044 & -0.046 & 0.001 \\
\hline \multicolumn{2}{|c|}{ Total $N_{\mathrm{A}}$} & 35 & 10 & 7 & 9 & 12 & 22 & 9 & 22 & 8.35 \\
\hline \multicolumn{2}{|c|}{ Mean Ho } & 0.753 & 0.551 & 0.384 & 0.584 & 0.669 & 0.747 & 0.706 & 0.765 & 0.635 \\
\hline \multicolumn{2}{|c|}{ Mean He } & 0.834 & 0.512 & 0.354 & 0.548 & 0.686 & 0.756 & 0.670 & 0.780 & 0.644 \\
\hline
\end{tabular}


Table 6. Platichthys flesus. Genetic differentiation (microsatellites) of the studied populations. Single- and multi-locus global assessment of genetic differentiation between samples using: (1) $F_{\text {ST }}$ estimated with Weir \& Cockerham 's $\theta$ and tested using 10,000 permutations $(* p<0.05 ; * * * p<0.001)$ and (2) exacts tests of genetic differentiation tested with the Markov chain method using 5,000 iterations (bold indicates significant q-values)

\begin{tabular}{llllllllll}
\hline & STPFL001 & PFSCU4 & PFSCU3 & STPFL025 & PFSCU7 & PFSCU1 & PFSCU8 & STPFL004 & All loci \\
\hline$\theta$ & $\mathbf{0 . 0 3 0} * * *$ & 0.008 & 0.005 & -0.002 & $\mathbf{0 . 0 1 2} * * *$ & $\mathbf{0 . 0 0 7} *$ & 0.027 & $\mathbf{0 . 0 0 8} *$ & $\mathbf{0 . 0 1 0} *$ \\
Exact test & $\mathbf{0 . 0 0 0}$ & $\mathbf{0 . 0 1 4}$ & $\mathbf{0 . 0 1 1}$ & 0.077 & $\mathbf{0 . 0 0 2}$ & $\mathbf{0 . 0 0 0}$ & 0.131 & $\mathbf{0 . 0 0 0}$ & $\mathbf{0 . 0 1 0}$ \\
\hline
\end{tabular}

Table 7. Platichthys flesus. Genetic differentiation (microsatellites) of the studied populations. Estimation of $F_{\mathrm{ST}}(\theta$; above diagonal) and exact tests of genetic differentiation (below diagonal) for each pair of locations. Pairwise $\theta$ values were calculated according to Weir \& Cockerham and were tested using 10,000 permutations $(* \mathbf{p}<0.05 ; * * p<0.01 ; * * * p<0.001)$. Pairwise exact tests were tested using the Markov chain method with 5000 iterations (bold indicates significant q-values)

\begin{tabular}{llllll} 
& Tamar & Canche & Seine & Vilaine & Mondego \\
\hline Tamar & - & -0.002 & 0.001 & 0.002 & $\mathbf{0 . 0 2 1} * * *$ \\
Canche & 0.931 & - & 0.001 & $\mathbf{0 . 0 0 5} * *$ & $\mathbf{0 . 0 2 7} * * *$ \\
Seine & $\mathbf{0 . 0 0 9}$ & $\mathbf{0 . 0 0 0}$ & - & 0.004 & $\mathbf{0 . 0 2 2} * * *$ \\
Vilaine & 0.129 & $\mathbf{0 . 0 0 0}$ & $\mathbf{0 . 0 0 0}$ & - & $\mathbf{0 . 0 1 3} * * *$ \\
Modego & $\mathbf{0 . 0 0 0}$ & $\mathbf{0 . 0 0 0}$ & $\mathbf{0 . 0 0 0}$ & $\mathbf{0 . 0 0 0}$ & - \\
\hline
\end{tabular}


Table 8. Platichthys flesus. Genetic diversity (AMPD1) of the studied populations. Number of alleles $\left(N_{\mathrm{A}}\right)$, observed $\left(H_{0}\right)$ and unbiased $\left(H_{e}\right)$ heterozygosities and $F_{I S}$ for each location and each locus. $F_{\text {IS }}$ was estimated according to Weir \& Cockerham and was tested using the Markov chain method with 5,000 iterations $(* p<0.05$; **p $<0.01$; ***p $<0.001)$. Bold indicates $\boldsymbol{F}_{\text {IS }}$ values that remained significant after qvalue correction. AMPD1: AMP-desaminase isoform 1

\begin{tabular}{|c|c|c|c|}
\hline \multirow{2}{*}{ Population } & \multirow{2}{*}{ Parameters } & \multicolumn{2}{|c|}{ AMPD1 } \\
\hline & & Locus 33 & Locus 96 \\
\hline \multirow[t]{4}{*}{ Tamar } & $N_{\mathrm{A}}$ & 2 & 2 \\
\hline & $\mathrm{H}_{\mathrm{o}}$ & 0.119 & 0.523 \\
\hline & $\mathrm{H}_{\mathrm{e}}$ & 0.113 & 0.413 \\
\hline & $\mathrm{F}_{\mathrm{IS}}$ & $-0.051 * * *$ & $-0.272 * * *$ \\
\hline \multirow[t]{4}{*}{ Canche } & $N_{\mathrm{A}}$ & 2 & 2 \\
\hline & $\mathrm{H}_{\mathrm{o}}$ & 0.163 & 0.306 \\
\hline & $\mathrm{H}_{\mathrm{e}}$ & 0.151 & 0.290 \\
\hline & $F_{\text {IS }}$ & $-0.079 * * *$ & -0.057 \\
\hline \multirow[t]{4}{*}{ Seine } & $N_{\mathrm{A}}$ & 2 & 2 \\
\hline & $\mathrm{H}_{\mathrm{o}}$ & 0.155 & 0.600 \\
\hline & $\mathrm{H}_{\mathrm{e}}$ & 0.145 & 0.480 \\
\hline & $F_{\text {IS }}$ & $-0.073 * * *$ & $-0.252 * * *$ \\
\hline \multirow[t]{4}{*}{ Vilaine } & $N_{\mathrm{A}}$ & 2 & 2 \\
\hline & $\mathrm{H}_{\mathrm{o}}$ & 0.250 & 0.364 \\
\hline & $\mathrm{H}_{\mathrm{e}}$ & 0.221 & 0.301 \\
\hline & $F_{\text {IS }}$ & $-0.132 * * *$ & $-0.211 * * *$ \\
\hline \multirow[t]{7}{*}{ Mondego } & $N_{\mathrm{A}}$ & 2 & 2 \\
\hline & $\mathrm{H}_{\mathrm{o}}$ & 0.120 & 0.420 \\
\hline & $\mathrm{H}_{\mathrm{e}}$ & 0.113 & 0.358 \\
\hline & $F_{\text {IS }}$ & $-0.054 * * *$ & $-0.176 * * *$ \\
\hline & Total $N_{\mathrm{A}}$ & 2 & 2 \\
\hline & Mean Ho & 0.16158 & 0.4427 \\
\hline & Mean $\mathrm{He}$ & 0.14902 & 0.36842 \\
\hline
\end{tabular}

Table 9. Platichthys flesus. Genetic differentiation (AMP-desaminase isoform 1, AMPD1) of the studied populations. Single- and multi-locus global assessment of genetic differentiation between samples using: (1) $F_{\mathrm{ST}}$ estimated with Weir \& Cockerham 's $\theta$ and tested using 10,000 permutations $(* p<0.05 ; * * p<$ $0.01 ; * * * p<0.001)$ and (2) exact tests of genetic differentiation tested with the Markov chain method using 5,000 iterations (bold indicates significant q-values)

\begin{tabular}{llll}
\hline & Locus 33 & Locus 96 & All loci \\
\hline$\theta$ & -0.006 & $\mathbf{0 . 0 3 3}^{*}$ & $\mathbf{0 . 0 2 1} *$ \\
Exact test & 0.539 & $\mathbf{0 . 0 0 4}$ & $\mathbf{0 . 0 1 8}$ \\
\hline
\end{tabular}


Table 10. Platichthys flesus. Genetic differentiation (AMP-desaminase isoform 1, AMPD1) of the studied populations. Estimation of $F_{\mathrm{ST}}(\theta$; above diagonal) and exact tests of genetic differentiation (below diagonal) for each pair of locations. Pairwise $\theta$ values were calculated according to Weir \& Cockerham and were tested using 10,000 permutations $(* p<0.05 ; * * p<0.01 ; * * p<0.001)$. Pairwise exact tests were tested using the Markov chain method with 5,000 iterations (bold indicates significant q-values)

\begin{tabular}{llllll}
\hline & Tamar & Canche & Seine & Vilaine & Mondego \\
\hline Tamar & - & $\mathbf{0 . 0 2 6} *$ & 0.015 & 0.021 & -0.000 \\
Canche & 0.079 & - & $\mathbf{0 . 1 0 1 * * *}$ & -0.009 & -0.001 \\
Seine & 0.198 & $\mathbf{0 . 0 0 1}$ & - & $\mathbf{0 . 0 9 1 * * *}$ & $\mathbf{0 . 0 5 0 * * *}$ \\
Vilaine & 0.147 & 1.000 & $\mathbf{0 . 0 0 2}$ & - & 0.002 \\
Mondego & 0.398 & 0.380 & $\mathbf{0 . 0 1 9}$ & 0.474 & - \\
\hline
\end{tabular}




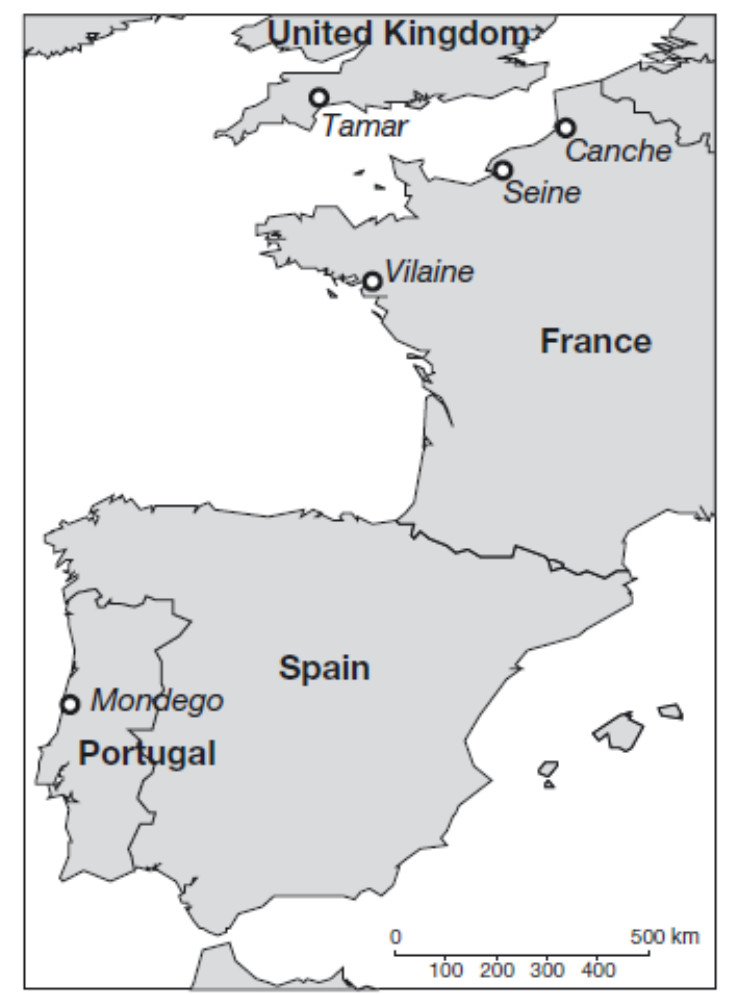

Figure 1: Platichthys flesus. Sampling locations of European flounder

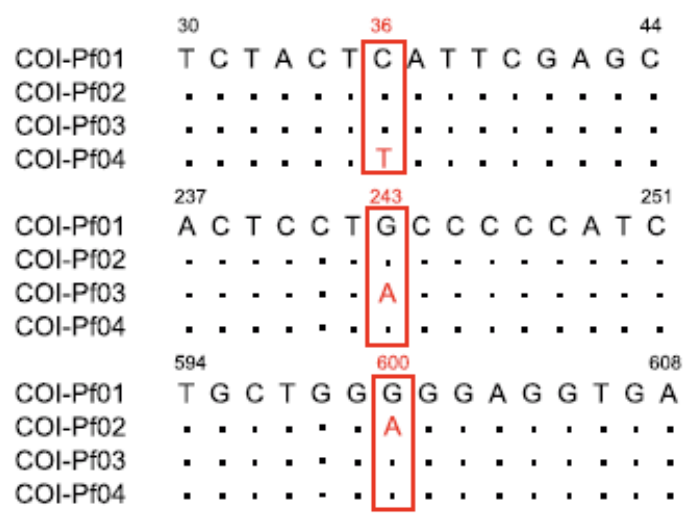

Figure 2: Platichthys flesus. Haplotype sequences of cytochrome $c$ oxidase subunit 1 (CO1). Values correspond to the numbering of the base pairs (bp) in the 689 bp sequences $\left(5^{\prime} 3^{\prime}\right)$ and the boxes indicate the position of the polymorphic sites. 


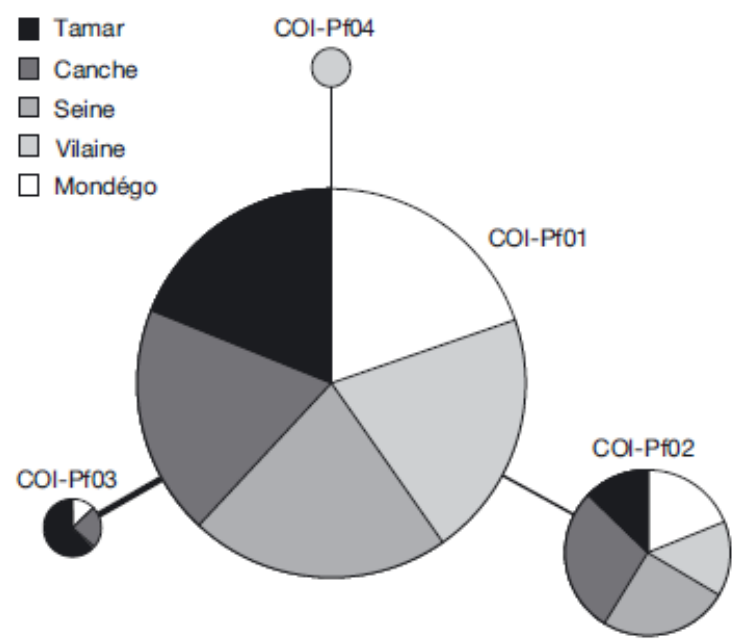

Figure 3: Platichthys flesus. Haplotype network of cytochrome $c$ oxidase subunit 1 (CO1) constructed with the parsimony method of Templeton et al. (1992) for 5 populations of European flounder

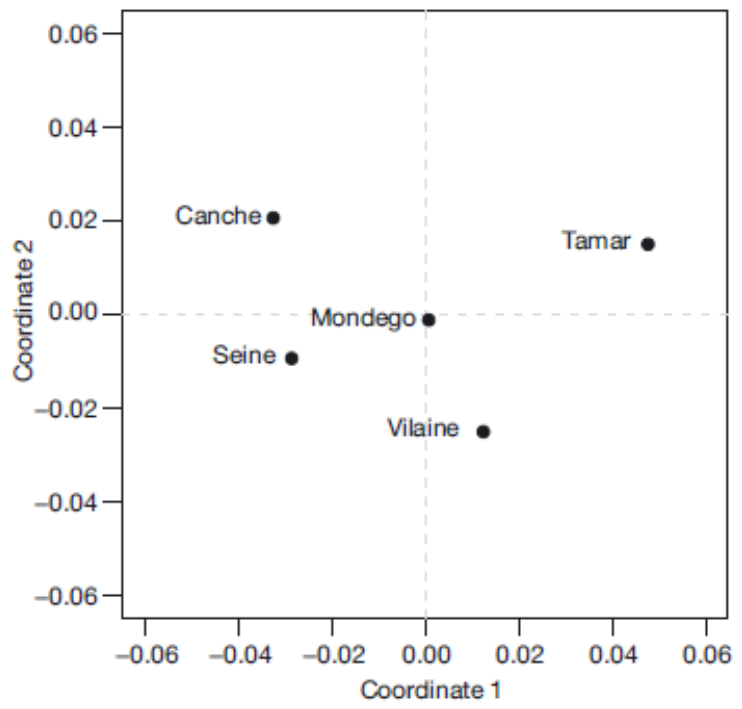

Figure 4: Platichthys flesus. Multi-dimensional scaling (MDS) on pairwise $\mathrm{F}_{\mathrm{ST}}$ (cytochrome $c$ oxidase subunit 1, $\mathrm{CO} 1)$ for the 5 populations studied

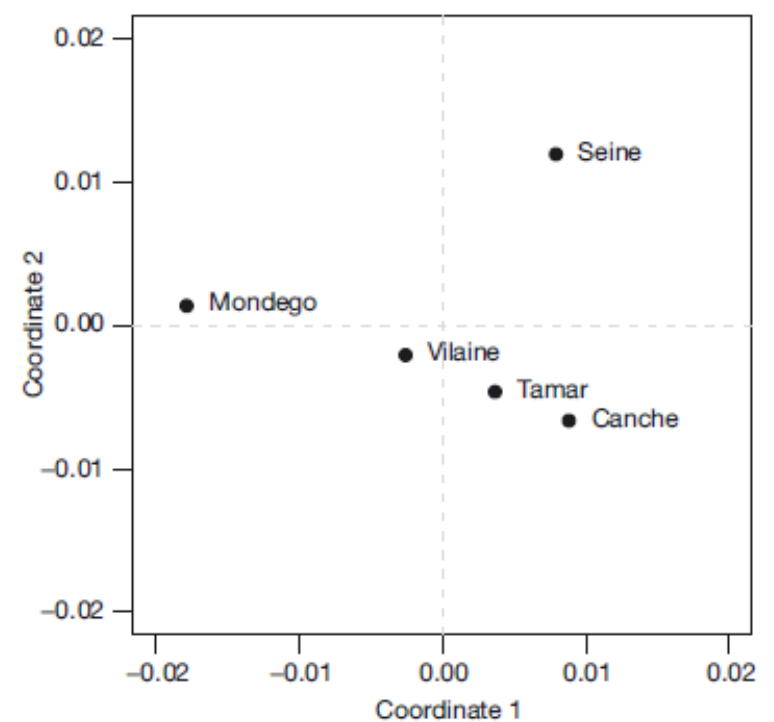

Figure 5: Platichthys flesus. Multi-dimensional scaling (MDS) on pairwise $\mathrm{F}_{\mathrm{ST}}$ (microsatellites) for the 5 populations studied 


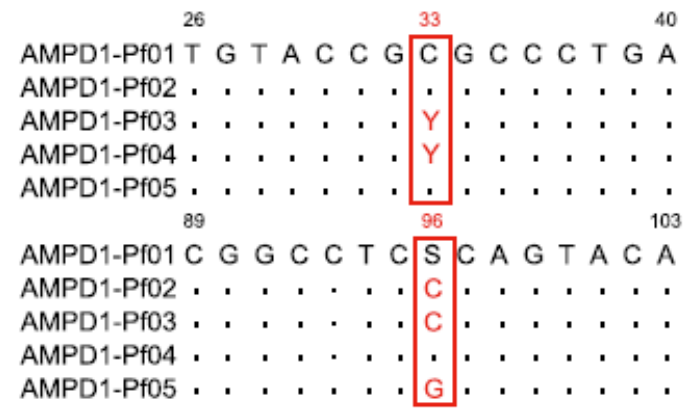

Figure 6: Platichthys flesus. Allelic sequences of AMP-desaminase isoform 1 (AMPD1). Values correspond to the numbering of the base pairs (bp) in the $160 \mathrm{bp}$ sequences ( $\left.5^{\prime} 3^{\prime}\right)$ and the boxes indicate the position of the polymorphic sites.

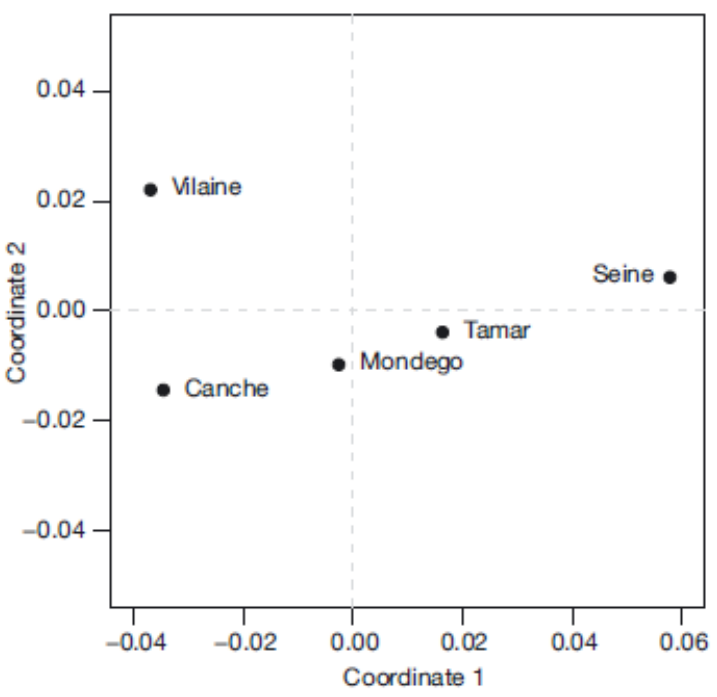

Figure 7: Platichthys flesus. Multi-dimensional scaling (MDS) on pairwise $\mathrm{F}_{\mathrm{ST}}$ (AMP-desaminase isoform 1, AMPD1) 
Appendix 1. Platichthys flesus. Sequences of different alleles of AMP-deaminase isoform 1 (AMPD1, 160 bp). Bold letters indicate the location of mutations

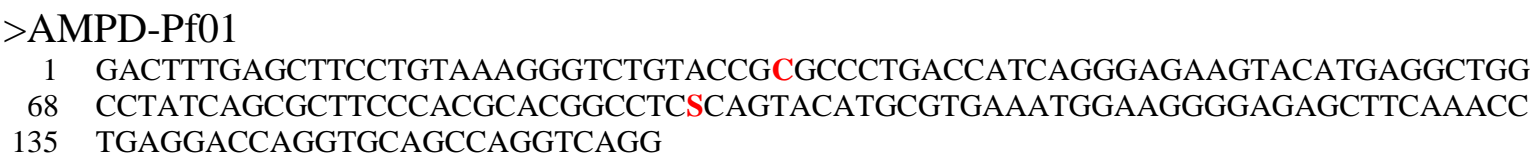

1 GACTTTGAGCTTCCTGTAAAGGGTCTGTACCGCGCCCTGACCATCAGGGAGAAGTACATGAGGCTGG 68 CCTATCAGCGCTTCCCACGCACGGCCTCSCAGTACATGCGTGAAATGGAAGGGGAGAGCTTCAAACC 135 TGAGGACCAGGTGCAGCCAGGTCAGG

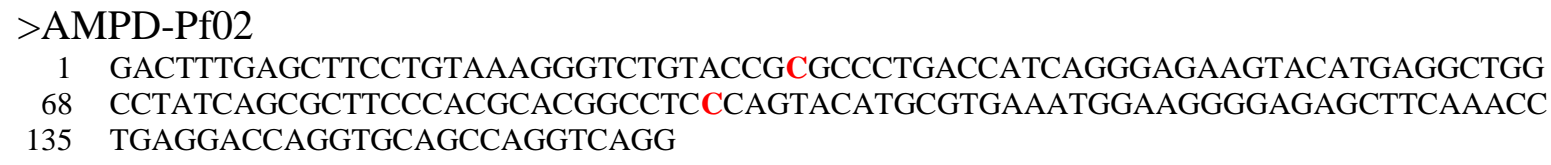

1 GACTTTGAGCTTCCTGTAAAGGGTCTGTACCGYGCCCTGACCATCAGGGAGAAGTACATGAGGCTGG 68 CCTATCAGCGCTTCCCACGCACGGCCTCCCAGTACATGCGTGAAATGGAAGGGGAGAGCTTCAAACC

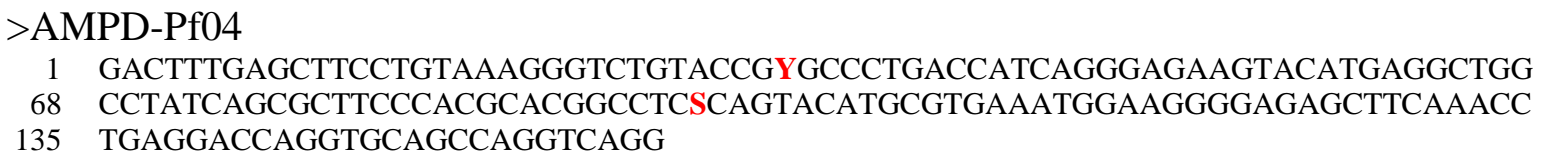

1 GACTTTGAGCTTCCTGTAAAGGGTCTGTACCGYGCCCTGACCATCAGGGAGAAGTACATGAGGCTGG 68 CCTATCAGCGCTTCCCACGCACGGCCTCSCAGTACATGCGTGAAATGGAAGGGGAGAGCTTCAAACC 135 TGAGGACCAGGTGCAGCCAGGTCAGG

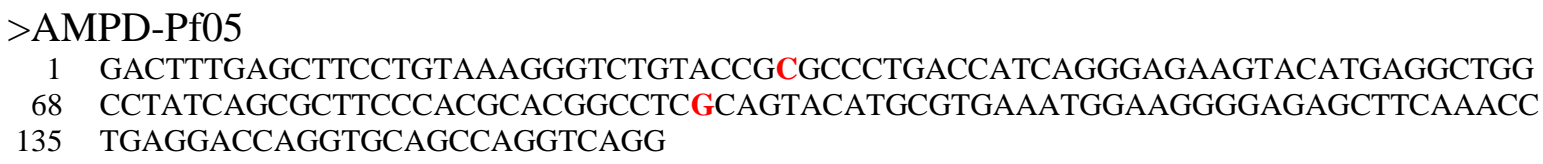

1 GACTTTGAGCTTCCTGTAAAGGGTCTGTACCGCGCCCTGACCATCAGGGAGAAGTACATGAGGCTGG 68 CCTATCAGCGCTTCCCACGCACGGCCTCGCAGTACATGCGTGAAATGGAAGGGGAGAGCTTCAAACC 135 TGAGGACCAGGTGCAGCCAGGTCAGG 